\title{
Aircraft routing with minimal climate impact: the REACT4C climate cost function modelling approach (V1.0)
}

\author{
V. Grewe ${ }^{1}$, C. Frömming ${ }^{1}$, S. Matthes ${ }^{1}$, S. Brinkop ${ }^{1}$, M. Ponater ${ }^{1}$, S. Dietmüller ${ }^{1}$, P. Jöckel ${ }^{1}$, H. Garny ${ }^{1}$, E. Tsati ${ }^{1}$, \\ K. Dahlmann ${ }^{1}$, O. A. Søvde ${ }^{2}$, J. Fuglestvedt ${ }^{2}$, T. K. Berntsen ${ }^{2}$, K. P. Shine ${ }^{3}$, E. A. Irvine ${ }^{3}$, T. Champougny $^{4}$, and \\ P. Hullah ${ }^{5}$ \\ ${ }^{1}$ Deutsches Zentrum für Luft- und Raumfahrt, Institut für Physik der Atmosphäre, Oberpfaffenhofen, Germany \\ ${ }^{2}$ Center for International Climate and Environmental Research Oslo (CICERO), Oslo, Norway \\ ${ }^{3}$ Department of Meteorology, University of Reading, Reading, UK \\ ${ }^{4}$ Eurocontrol Headquarter DNM/OPL, Brussels, Belgium \\ ${ }^{5}$ Eurocontrol Experimental Centre, Bretigny, France
}

Correspondence to: V. Grewe (volker.grewe@dlr.de)

Received: 1 August 2013 - Published in Geosci. Model Dev. Discuss.: 12 August 2013

Revised: 29 November 2013 - Accepted: 16 December 2013 - Published: 28 January 2014

\begin{abstract}
In addition to $\mathrm{CO}_{2}$, the climate impact of aviation is strongly influenced by non- $\mathrm{CO}_{2}$ emissions, such as nitrogen oxides, influencing ozone and methane, and water vapour, which can lead to the formation of persistent contrails in ice-supersaturated regions. Because these non- $\mathrm{CO}_{2}$ emission effects are characterised by a short lifetime, their climate impact largely depends on emission location and time; that is to say, emissions in certain locations (or times) can lead to a greater climate impact (even on the global average) than the same emission in other locations (or times). Avoiding these climate-sensitive regions might thus be beneficial to climate. Here, we describe a modelling chain for investigating this climate impact mitigation option. This modelling chain forms a multi-step modelling approach, starting with the simulation of the fate of emissions released at a certain location and time (time-region grid points). This is performed with the chemistry-climate model EMAC, extended via the two submodels AIRTRAC (V1.0) and CONTRAIL (V1.0), which describe the contribution of emissions to the composition of the atmosphere and to contrail formation, respectively. The impact of emissions from the large number of time-region grid points is efficiently calculated by applying a Lagrangian scheme. EMAC also includes the calculation of radiative impacts, which are, in a second step, the input to climate metric formulas describing the global climate impact of the emission at each time-region grid point. The result of the modelling chain comprises a four-dimensional data
\end{abstract}

set in space and time, which we call climate cost functions and which describes the global climate impact of an emission at each grid point and each point in time. In a third step, these climate cost functions are used in an air traffic simulator (SAAM) coupled to an emission tool (AEM) to optimise aircraft trajectories for the North Atlantic region. Here, we describe the details of this new modelling approach and show some example results. A number of sensitivity analyses are performed to motivate the settings of individual parameters. A stepwise sanity check of the results of the modelling chain is undertaken to demonstrate the plausibility of the climate cost functions.

\section{Introduction}

The anthropogenic origin of a substantial contribution to observed climate change is well established (e.g. IPCC, 2007). The challenge is how to deal with climate change and to find and evaluate mitigation strategies. Air traffic has a significant contribution to total anthropogenic climate change (IPCC, 1999; Berntsen and Fuglestvedt, 2008; Lee et al., 2010; Burkhardt and Kärcher, 2011) and a significant part of its contribution arises from non- $\mathrm{CO}_{2}$ emissions, e.g. from changes in ozone, methane, cloudiness and others. 
These non- $\mathrm{CO}_{2}$ effects are characterised by a high temporal and spatial variability; that is, their impact on climate depends not only on the amount of emitted species, as in the case of $\mathrm{CO}_{2}$, but also on the time and region where the emissions take place. The formation and persistence of contrails depend on both aircraft and fuel parameters and meteorological conditions (Schumann, 1996), such as ice supersaturation. These ice-supersaturated regions are locally and temporarily very confined and show a large variability (Spichtinger et al., 2003; Gierens and Spichtinger, 2000) and a dependence on the prevailing weather conditions (Irvine et al., 2012). Contrails may persist for a long time under favourable weather conditions (Minnis et al., 1998; Burkhardt and Kärcher, 2009). The variability of the climate impact from $\mathrm{NO}_{\mathrm{x}}$ emissions with respect to weather conditions has not been investigated yet. Climatological studies (Grewe and Stenke, 2008; Köhler et al., 2008; Frömming et al., 2012) show a distinct altitude and latitude variability. For an individual weather situation this variability is probably enlarged for all non- $\mathrm{CO}_{2}$ effects. For example, $\mathrm{NO}_{\mathrm{x}}$ emissions which take place in a region with cloud formation and rain will have a significantly lower impact than an emission taking place in a region with upwelling, increasing the lifetime of the emitted species.

Within the EU project REACT4C (http://www.react4c.eu/; for abbreviations see Table A1), we quantify this variability and use it to develop possible strategies whereby aircraft are routed to minimise their total climate impact. It is likely that the fuel consumption increases for these aircraft trajectories, because in general (although not always) aircraft currently take routes that are close to the minimum fuel (and hence minimum $\mathrm{CO}_{2}$ emission) route. In the case of climateoptimal routing, the gain from non- $\mathrm{CO}_{2}$ effects counteracts the $\mathrm{CO}_{2}$ induced warming, at least to some extent. How strong the compensating gain from the avoidance of non- $\mathrm{CO}_{2}$ climate effects needs to be also depends on the objective. It will need to be stronger if the objective is on long-term climate change, since $\mathrm{CO}_{2}$ effects are then more pronounced. Thereby the choice of climate-optimal route depends on the chosen time frame (or time horizon) and the adopted indicator of climate change.

Basically this optimisation is based on two major steps, i.e. the calculation of

1. climate cost functions and

2. aircraft trajectories optimised on the basis of the climate cost functions,

where the climate cost functions (CCF) are specific climate metrics, i.e. climate impacts per unit emission. The idea of weather-specific re-routing of air traffic for the benefit of climate has been addressed before (Sausen et al., 1994; Mannstein et al., 2005; Schumann et al., 2011; Sridhar et al., 2012). However, none of these studies included such a broad range of effects, as addressed in this study: contrails, carbon dioxide, ozone, methane, ozone from methane changes, and water vapour. The changes in ozone arising from changes of its precursor methane are also called primary-mode ozone (PMO).

The idea of REACT4C (Matthes, 2012; Matthes et al., 2012) is first to concentrate on frequently occurring daily weather patterns (Irvine et al., 2013), for which a detailed analysis is performed with a new modelling approach, which we describe here in detail. Results will be published in companion papers. The methodology is outlined in Figs. 1 and 2. As a first step, we are concentrating on the North Atlantic region, including most of Europe and North America. For this region a weather classification is performed taking into account specific air traffic routes (Irvine et al., 2013). For each type of weather pattern a representative weather pattern is selected. For this 1-day weather pattern, a time-region grid (Fig. 3) is defined and for each time-region grid point the global climate impact of an emission is calculated for different emission times. The time-region grid covers the flight tracks over the North Atlantic and the main cruise levels.

The climate cost functions are calculated with the chemistry-climate model EMAC (version 2.42), which additionally includes two important submodels: ATTILA, a Lagrangian transport scheme (Reithmeier and Sausen, 2002) and AIRTRAC (version 1.0, Frömming et al., 2013; see Supplement), which calculates contributions from additional emissions to concentrations based on ATTILA. The EMAC submodel AIRTRAC is specifically developed for this study and described in Sect. 3. The determination of the climate cost functions (Fig. 1, highlighted box in the left column) includes first the calculation of the contributions of additional emissions to atmospheric concentrations (nitrogen oxides, ozone, methane, contrails, water vapour, carbon dioxide) and contrail properties, and second the calculation of the radiative impact over a time period of weeks leading to an approximate annual mean instantaneous radiative forcing. Third, we use a correlation between instantaneous and adjusted radiative forcing to obtain the latter as a more reliable basis for the expected climate change (Sect. 3.4). This is eventually used as input to climate response formulas to obtain a set of metrics per unit emission, i.e. climate cost functions, which is interpolated back to the original EMAC grid.

In Sect. 3.5 we relate individual metrics to political objectives and optimisation problems. The climate cost functions are used in the next step (Fig. 1) by a flight planning tool (SAAM) to obtain aircraft trajectories and respective emissions as well as the reduction in the climate impact due to the operational changes in aircraft trajectories. The climate cost function approach aims at reducing the contribution of air traffic on climate. The results for individual weather patterns can be multiplied by their frequencies to obtain an estimate of the total climate impact reduction as a result of the REACT4C re-routing strategy. Since this leads to changes in the background concentration and production efficiencies, e.g. ozone production per $\mathrm{NO}_{\mathrm{x}}$ molecule, other emitters such 


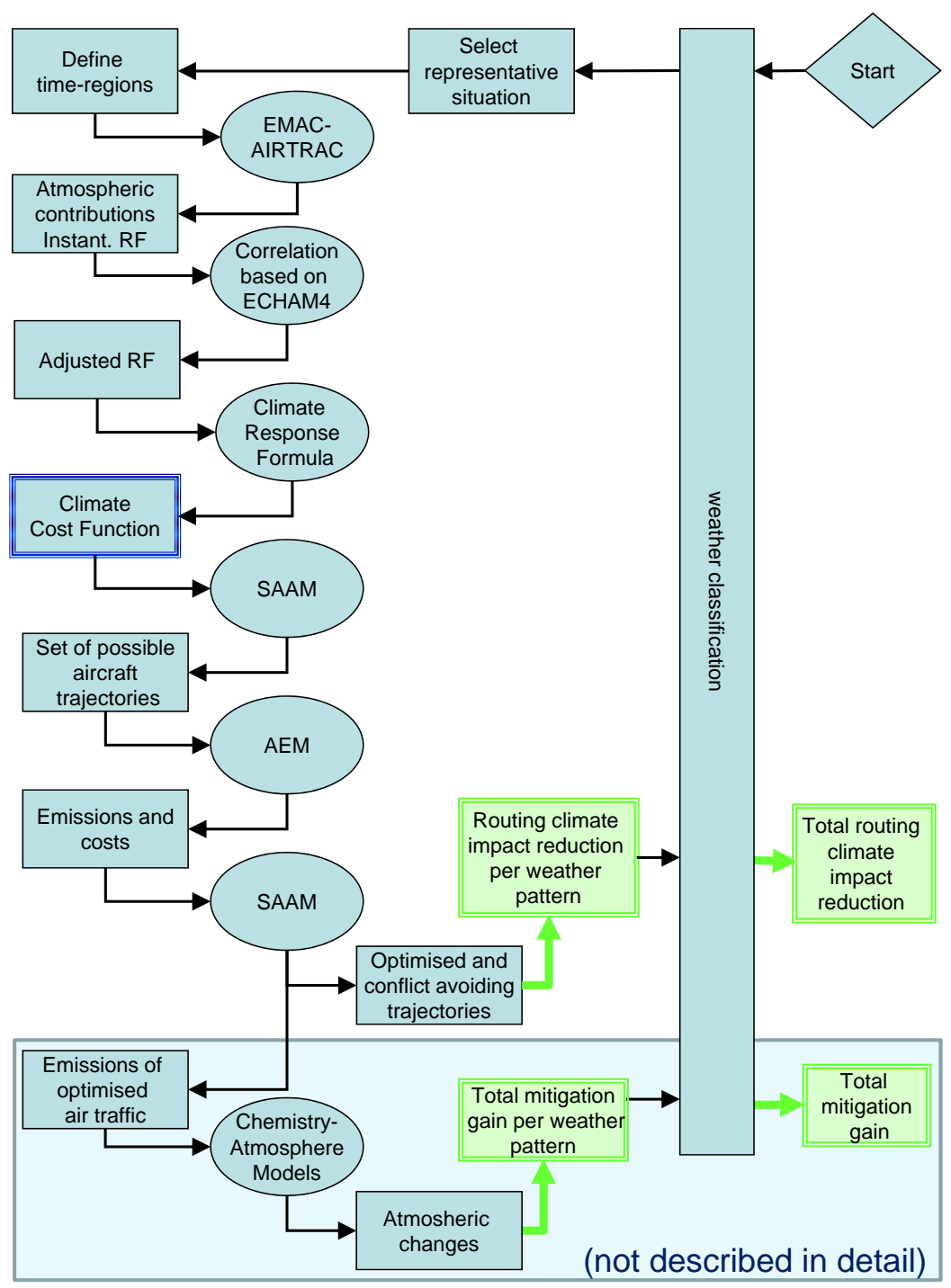

Fig. 1. Illustration of the model chain. Models are given in the ovals. Data and definitions are given in rectangles. Climate cost functions are highlighted (dark blue), as are major results (green). The light-blue box at the bottom indicates a possible extension of the modelling chain, which is not covered here.

as industry or traffic might have a larger climate impact (Grewe et al., 2012a). This can be investigated by applying atmospheric-chemistry models to obtain the total mitigation gain (Fig. 1, green boxes). This is planned in the project REACT4C, but is not part of this publication (light-blue box in Fig. 1).

The whole methodology is based on operational models which were extended. The operational models are briefly introduced in Sect. 2, and the new modelling approaches are described in detail in Sect. 3 (climate cost functions). In Sect. 4 we provide a comparison to other studies and a sanity check of our modelling approach.

\section{Base models}

The REACT4C modelling approach is based on a number of models which have been applied many times previously. These models are combined with new approaches. Therefore we only briefly describe the base models and concentrate on a detailed description of the new approaches in Sect. 3.

\subsection{Atmosphere: EMAC}

The ECHAM/MESSy Atmospheric Chemistry (EMAC) model (here version 2.42) is a numerical chemistry and climate simulation system that includes submodels describing tropospheric to middle-atmospheric processes and their 


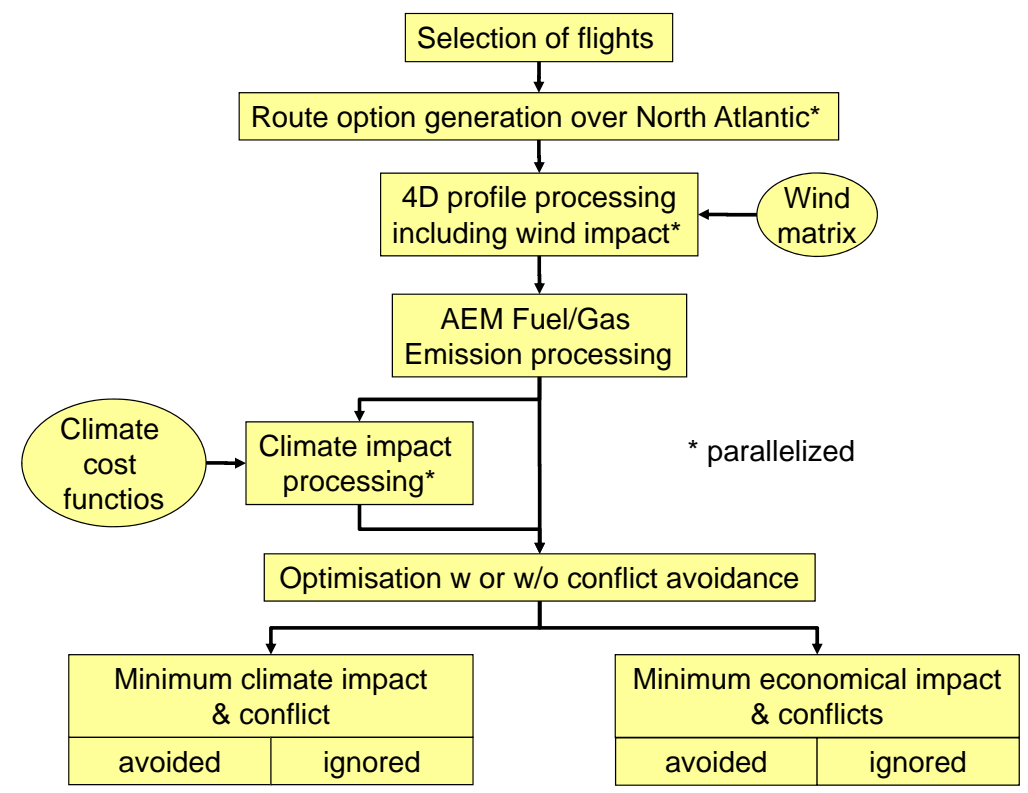

Fig. 2. Illustration of the SAAM and AEM model interaction.

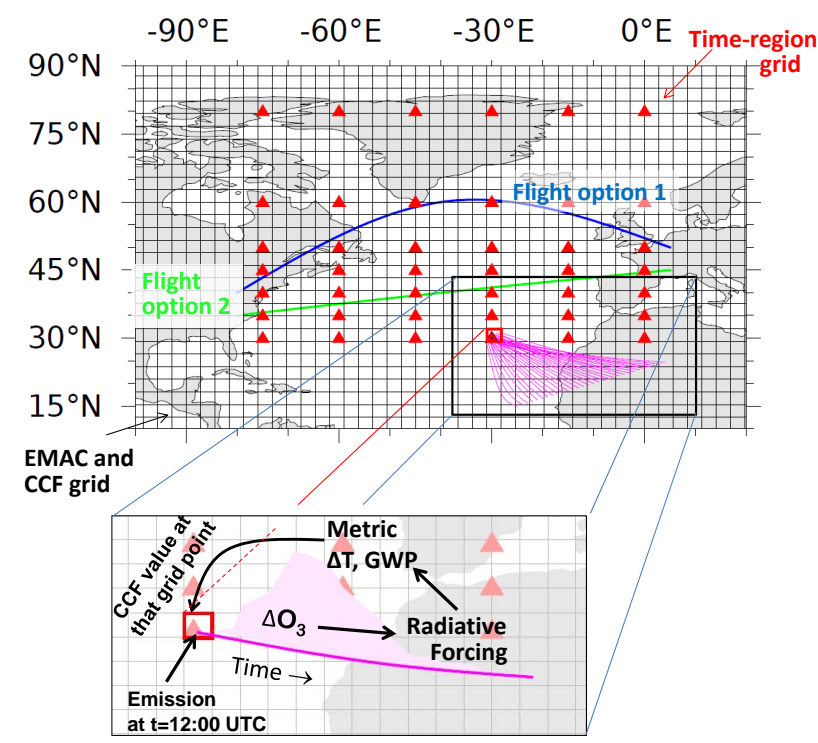

Fig. 3. Latitude-longitude grid of the climate cost function (CCF) and EMAC grid (black) and location of the time-region centres (red triangles). Air parcel trajectories started from the EMAC grid cell in which the time-region grid point is located; these trajectories are given in magenta for one grid point only. Two flight options are shown as examples in blue and green. Inlay: the climate cost function calculation is shown as an example for one air parcel trajectory.

interaction with oceans, land and human influences (Jöckel et al., 2006). Here we use the second version of the Modular Earth submodel System (MESSy2) to link the individual physical and chemical processes described in submodels
(Jöckel et al., 2010). The MESSy interface also provides standard and well-tested routines, such as those for data extraction and grid remapping, which facilitates the implementation of new submodels. We run the model in a T42L41 resolution, which is approximately $2.8^{\circ} \times 2.8^{\circ}$ latitude-longitude resolution and 41 layers in the vertical from the surface to an upper layer centred at $5 \mathrm{hPa}$.

The core model for the atmosphere is the fifth generation European Centre Hamburg general circulation model ECHAM5 (Roeckner et al., 2006). The chemistry is described by the submodel MECCA (version 3.2) (Sander et al., 2011). More detailed information, including references, about the model system is available from http://www. messy-interface.org.

\subsection{Aircraft routing and emissions}

The simulation of the flow of air traffic is performed with the System for traffic Assignment and Analysis at a Macroscopic level (SAAM) to which the Advanced Emission Model (AEM) is coupled. An overview on the simulation system SAAM and AEM is given in Fig. 2 and discussed in more detail in Sect. 2.2.3.

\subsubsection{SAAM}

The integrated system SAAM, version 4.2.0 (Eurocontrol, 2012), is built for wide or local design, evaluation, analysis and presentation of air traffic airspace scenarios (http://www.eurocontrol.int/nm-services/saam-systemtraffic-assignment-and-analysis-macroscopic-level). It allows for the creation, change and design of air traffic route networks with their possible associated constraints (e.g. 

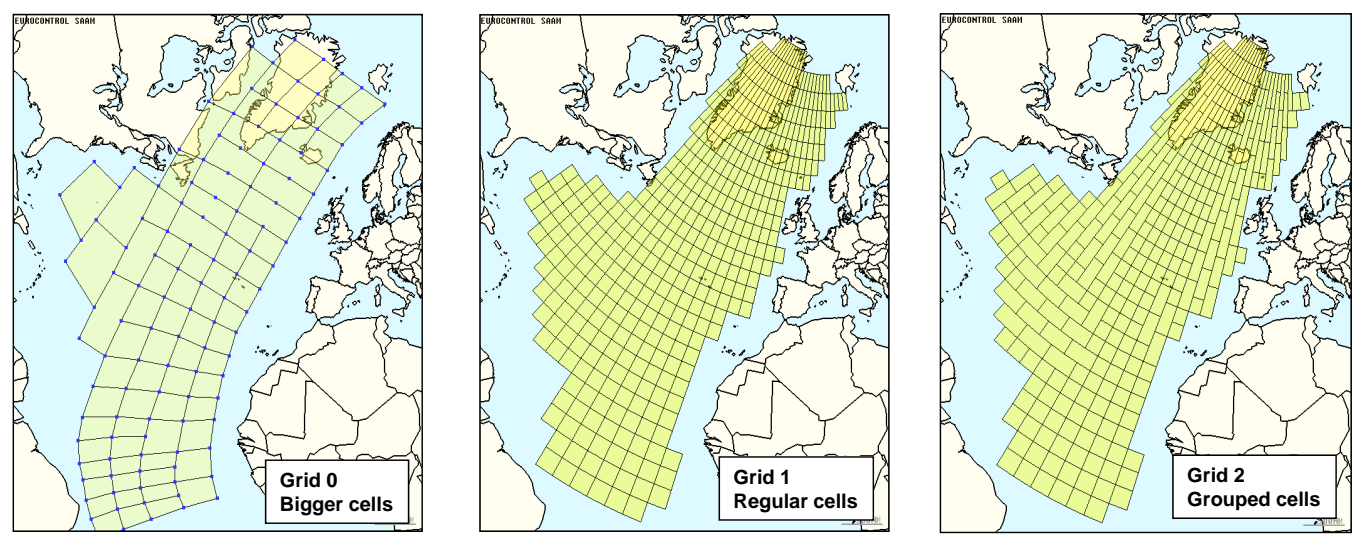

Fig. 4. Different SAAM grid resolutions for route generation.

restrictions from the route availability document - RAD or flight level constraints). From any traffic demand (basically worldwide airport origins and destinations, aircraft types and departure times), a set of full 4-D aircraft trajectories (space and time) is generated.

The best choice of these 4-D aircraft trajectories is made using optimisation with an objective function minimising a mathematical cost that can be based on either economical values derived from flight time and aircraft operating cost or on the climate impact (see below). Constraints concerning conflict avoidance between all 4-D aircraft trajectories can be switched on or off in the optimisation model. Climate impact minimisation has not been performed before with SAAM, but other optimisation problems were considered, for instance a balancing of the air traffic controller's work load (Champougny et al., 2001).

Aircraft performance included in SAAM uses Base of Aircraft Data (BADA) version 3.9 (see http://www.eurocontrol. int/services/bada), which also provides fuel flow based on aircraft-engine characteristics and assumptions like mean aircraft load and weight.

\subsubsection{AEM}

The advanced emission model (AEM 2.5.0) has been developed to estimate the mass of fuel burnt, and emissions produced by a specific aircraft-engine configuration for a specific 4-D aircraft trajectory (Eurocontrol, 2013). Emissions are calculated for $\mathrm{CO}_{2}, \mathrm{H}_{2} \mathrm{O}, \mathrm{NO}_{\mathrm{x}}, \mathrm{SO}_{\mathrm{x}}, \mathrm{CO}$ and unburned hydrocarbons (HC), e.g. benzene (see also http: //www.eurocontrol.int/services/advanced-emission-model).

\subsubsection{Application of SAAM with AEM}

Figure 2 shows, in more detail, the information flow and coupling of SAAM and AEM. First, flights are selected from a database - including the city pair connection, departure time and aircraft and a reference aircraft trajectory calculated
- based on minimum costs. Second, routes are generated randomly. Here we apply a procedure which generates alternative routes by blocking of air space areas in addition to a randomly changed cruise altitude. Three different grid sizes (Fig. 4) for the blocking of the air space were tested. The SAAM standard grid size (grid 0) leads to significant deviations from the great circle, whereas the smaller cells only provide small deviations. Hence, the resolution with the larger grid cells (grid 0) is better suited for the generation of alternative routes and taken for the optimisation. This procedure leads to a randomly chosen variation of 16 additional routes in the horizontal with 4 additional options for the cruise altitude ( 3 below the original cruise level and 1 above) and hence $84(17 \times 5-1)$ alternative routings for each reference flight (i.e. city pair connection for a specific time). The number of the blocked grid cells has been varied to test the sensitivity of this parameter to the optimisation process. We found that an increase in the number of blocked cells to 18 only shows a minor change in the optimal solution with differences well below $1 \%$.

The third step (Fig. 2) is the calculation of the 4-D aircraft trajectory, which includes a performance calculation and takes into account wind fields. This is followed by the fourth step, namely the calculation of the emissions by using the AEM model. This leads to a large set of aircraft trajectories. Based on these data, an optimal air traffic flow is determined. The optimisation is either done with respect to economic or climate costs (climate impact). In the case of ignoring any conflicts, the optimisation simply chooses the minimum among the alternative routes for every reference flight (i.e. city pair connection at a specific time). In the case of conflict avoidance, the routes depend on each other and a linear programming is applied: 


$$
\begin{aligned}
& \min \sum_{i, j} R_{i j} C_{i j} \\
& \text { subject to } \\
& \mathrm{CM}_{i j k l} \leq 0 \forall i, j, k, l \text { conflict avoidance, } \\
& \sum_{i}^{n} R_{i j}=1 \quad \forall j \quad \text { one route option per flight, } \\
& R_{i j} \in\{0,1\} \quad \forall i, j \quad \text { route option variable, }
\end{aligned}
$$

with the flight index $i$ (and $k$, respectively): $1 \leq i \leq n$ ( $n$ is the number of city pair connections), $j$ ( $l$, respectively) the route option index ( $\leq 85$; see above), the precalculated conflict matrix $\mathrm{CM} \geq 0$ (i.e. number of conflicts) and the costs $C_{i, j}$. These costs are either defined for economic optimisation or climate optimisation. For economic optimisation the costs are

$C_{i, j}=F_{i, j} C^{\text {fuel }}+T_{i, j} C^{\text {time }}$,

with $F_{i, j}$ and $T_{i, j}$ the fuel consumption and flight time on route option $(i, j)$ in $[\mathrm{kg}]$ and [min], respectively, and $C^{\text {fuel }}=$ EUR $0.75 \mathrm{~kg}^{-1}, C^{\text {time }}=$ EUR $25 \mathrm{~min}^{-1}$. For climate optimisation the costs are defined as

$$
\begin{aligned}
C_{i, j}=\sum_{m} & {\left[M^{\mathrm{AiC}}\left(x_{m}\right) \quad D_{m}\right.} \\
& +M^{\mathrm{O}_{3}}\left(x_{m}\right) N_{m} \\
& +M^{\mathrm{CH}_{4}}\left(x_{m}\right) N_{m} \\
& +M^{\mathrm{PMO}}\left(x_{m}\right) N_{m} \\
& +M^{\mathrm{H}_{2} \mathrm{O}}\left(x_{m}\right) F_{m} \\
& \left.+M^{\mathrm{CO}_{2}}\left(x_{m}\right) F_{m}\right],
\end{aligned}
$$

where the aircraft trajectory of route option $(i, j)$ is divided into flight legs with index $m$, which is of the order of $10^{3}$. Each flight leg has a centre location $x_{m}$, a distance flown $D_{m}[\mathrm{~km}]$, fuel consumption $F_{m}[\mathrm{~kg}]$, and a $\mathrm{NO}_{\mathrm{x}}$ emission $N_{m}[\mathrm{kgN}]$, which are multiplied by the respective climate cost functions with a certain metric $M^{\text {species }}$ for the individual species (AiC is aircraft-induced cloudiness, i.e. contrails and contrail cirrus). See also next section for climate cost functions and metrics.

\section{Methodology: climate cost functions}

In this section we describe the calculation of the climate cost functions, starting with the Lagrangian approach and then followed by the definition of the time-region grid points and the chemistry and microphysics of the atmospheric processes, radiation changes and the climate impact calculations. A summary is presented in Sect. 3.6 and Table 1. The atmospheric process modelling is performed in the EMAC submodels AIRTRAC and CONTRAIL. Further documentation of the program structure, subroutines and namelists is given in the Supplement.

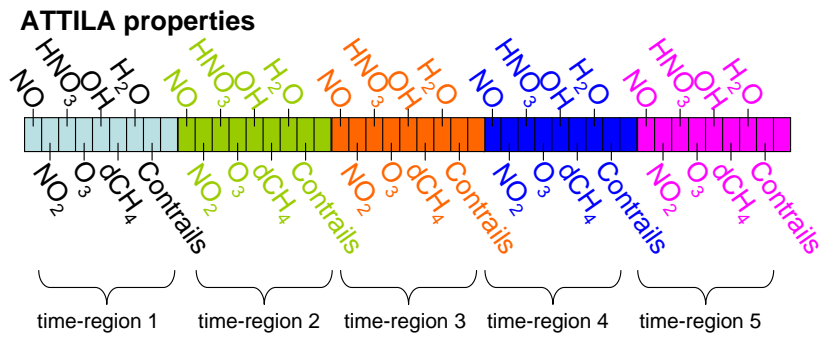

Fig. 5. Properties of an individual Lagrangian air parcel (trajectory) in the submodel AIRTRAC. The possibility to calculate numerous time-region grid point emissions in one simulation is a key aspect for computationally efficient coding.

\subsection{A Lagrangian approach: trade-off between computational efficiency and process accuracy}

The calculation of climate cost functions requires a calculation for each of the predefined time-region grid points. Hence, the desired resolution of the climate cost function in time and space determines the number of climate cost function calculations. We denote the number of time-region grid points by $N_{\mathrm{TR}}$ and denote the individual time-region grid points by $\mathrm{TR}_{i}\left(i=1, \ldots, N_{\mathrm{TR}}\right)$.

We chose a Lagrangian approach since it allows the inclusion of a multitude of cost function calculations in a single EMAC simulation. Each air parcel trajectory is characterised by its position at any time and includes an arbitrary number of properties $P$. We assign for each time-region grid points $\mathrm{TR}_{i}$ a set of $n$ properties, i.e. $P((i-1) \cdot n+1), \ldots, P(i \cdot n)$. Figure 5 shows examples for five time-region grid points (each coloured differently) a set of eight properties, namely the contribution of the emissions to the chemical species NO, $\mathrm{NO}_{2}, \mathrm{HNO}_{3}, \mathrm{O}_{3}, \mathrm{CH}_{4}$, and $\mathrm{H}_{2} \mathrm{O}$ and contrail coverage (see Supplement for a complete list of the 13 (nlgtrac=13) properties).

The Lagrangian approach is based on detailed modelling of the background processes within EMAC and an additional, and to some degree simplified, simulation of the contributions from emissions taking place in the respective time regions. Information from the detailed modelling is transferred to the air parcel trajectories and the contributions are calculated based on the results from the detailed process modelling within EMAC.

In principle two modelling approaches are applicable: (1) the Lagrangian approach introduced above and (2) a perturbation approach, which includes a base case simulation as well as an additional full simulation with the base model (here EMAC) for each time region, including additional emissions from the time region. Here we chose the Lagrangian approach since it better meets our objective: obviously the Lagrangian approach has the advantage of being numerically efficient, since many time regions are calculated 


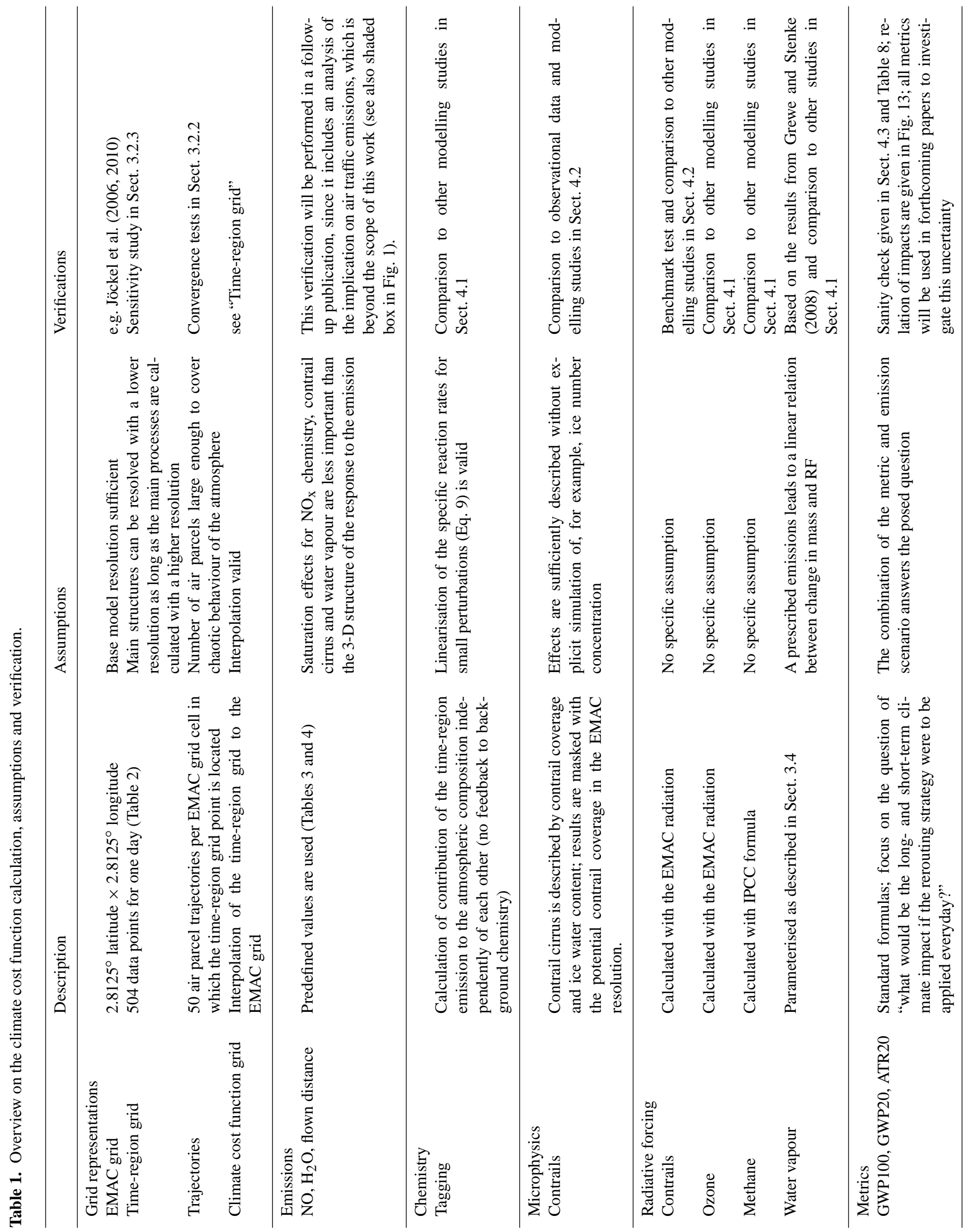


in parallel. The approach further calculates the contribution of an emission in the time region and separates it from compensating effects through changes in contribution from other sectors caused by non-linear processes, e.g. chemical saturation effects. On the other hand, the processes for the calculation of the time-region contributions are less detailed than the representation of the background processes in the base model EMAC.

The overall objective of our modelling approach is to minimise the contribution of air traffic to climate change. It is important to stress that the contribution calculation (Grewe et al., 2010) is much better suited to address this objective than the perturbation method, since it does not lead to misinterpretations of the results due to non-linear compensation effects in the chemistry (Grewe et al., 2012a).

Changes from the time-region emissions do not feed back to the base model processes. This ensures an identical background meteorology and chemistry for all time-region simulations; that is, we perform quasi-chemical-transport model (QCTM) simulations (Deckert et al., 2011).

The second approach, perturbation simulations for each time region, would have the advantage of having the same degree of detail in the description of background processes and the perturbation. However, it is extremely time- and resourceconsuming, and only its total impact is calculated, not the contribution of the time region (see above and also Grewe et al., 2010, 2012a; Grewe, 2013).

\subsection{Time regions and emissions}

\subsubsection{Definition}

Figure 3 shows the various grids used in our approach. The EMAC grid has a resolution of approximately $2.8^{\circ}$ longitude $\times 2.8^{\circ}$ latitude (black). On this grid we overlay the timeregion grid (red triangles), covering the North Atlantic region for the area where the optimisation with SAAM is performed (see Sect. 2.2.3). It consists of six longitudes, seven latitudes and four pressure levels for three points in time (see Table 2 for details). This comprises 504 grid points, meaning 504 calculations for the impact of emissions on the atmosphere have to be performed. We take into account water vapour emissions and nitrogen oxide emissions (see Table 3). The emissions are released for one time step (15 min) in the EMAC gridbox, in which the respective time-region grid point is located. Additionally, we consider properties of conventional present-day aircraft and fuel, such as the aircraft's overall propulsion efficiency, the combustion heat and the water vapour emission index (see Table 3).

For each time-region grid point, emissions are partitioned on 50 air parcel trajectories (see also inlay in Fig. 3), which are randomly distributed in the EMAC grid box in which the time-region grid point is located. Technically this is handled via the submodel TREXP and controlled by a namelist (Jöckel et al., 2010). Then the impact of emissions
Table 2. Definition of the time-region grid.

\begin{tabular}{lcll}
\hline Dimension & Number & Unit & Values \\
\hline Longitude & 6 & ${ }^{\circ} \mathrm{W}$ & $75,60,45,30,15,0$ \\
Latitude & 7 & ${ }^{\circ} \mathrm{N}$ & $30,35,40,45,50,60,80$ \\
Pressure & 4 & $\mathrm{hPa}$ & $400,300,250,200$ \\
Time & 3 & UTC & $6,12,18$ \\
\hline
\end{tabular}

is calculated by the AIRTRAC submodel (box model on the air parcel trajectories), the radiative forcing calculated and the climate impact (measured by climate metrics; see also Fig. 1) is associated with the time-region grid point. Finally these climate impact data on the time-region grid are interpolated to the EMAC grid, which is then the final climate cost function grid (Fig. 3).

\subsubsection{Sensitivity to the number of air parcel trajectories}

Here we investigate the number of air parcel trajectories at each emission point that are required in order to obtain unambiguous results. If the number of air parcel trajectories is too low, then only a few possible paths for the air parcels carrying the emission will be considered, and thus the results can become very noisy and random.

For this sensitivity study, 50 air parcel trajectories were released for 24 of the time-region grid points, located at $200 \mathrm{hPa}$ at $45^{\circ} \mathrm{N}$ and $50^{\circ} \mathrm{N}$ and at $400 \mathrm{hPa}$ at $40^{\circ} \mathrm{N}$ and $35^{\circ} \mathrm{N}$. For each of these time-region grid points, the mean $\mathrm{NO}_{\mathrm{x}}\left(\mathrm{NO}+\mathrm{NO}_{2}\right)$ mixing ratio over the first month of integration (i.e. January) was calculated over all 50 air parcel trajectories. We tested how strongly the results differ when less (between 2 and 48) air parcel trajectories were released. For each number of air parcel trajectories (between 2 and 48) 100 sub-samples out of the total 50 air parcel trajectories were randomly generated. For each sub-sample, the mean $\mathrm{NO}_{\mathrm{x}}$ mixing ratio was calculated and compared to the mean over all 50 air parcel trajectories. The relative deviations for these sub-samples as a function of number of air parcel trajectories is shown for one time-region grid point in Fig. 6 (top, left). Mean $\mathrm{NO}_{\mathrm{x}}$ values differ by up to $40 \%$ from the result for all 50 air parcel trajectories if only 2 air parcel trajectories are used. With an increasing number of air parcel trajectories, the deviations decrease and converge towards the mean value over 50 air parcel trajectories. The same diagnostic is shown for the corresponding mean ozone mixing ratios (Fig. 6, upper right). This diagnostic shows a similar behaviour to $\mathrm{NO}_{\mathrm{x}}$, but with a smaller initial spread in the results for small numbers of air parcel trajectories. In the bottom panel of Fig. 6, the standard deviation as a function of the number of air parcel trajectories shows a sharp decrease of the $\mathrm{NO}_{\mathrm{x}}$ and ozone standard deviation from around $20 \%$ to $5 \%$ and $12 \%$ to $4 \%$, respectively, up to an air parcel trajectory number of around 20. This figure confirms that the deviation in the results of ozone is smaller than in the $\mathrm{NO}_{\mathrm{x}}$ values also for the mean 
Table 3. Emissions and aircraft/fuel parameters.

\begin{tabular}{|c|c|c|c|}
\hline Parameter & Units & Value & Comment \\
\hline $\mathrm{NO}_{\mathrm{x}}$ emission & $\operatorname{kg}(\mathrm{NO})$ & $5 \times 10^{5}$ & $\begin{array}{l}\text { Equals } 2.33 \times 10^{5} \mathrm{~kg}(\mathrm{~N}) \text { and takes place } \\
\text { during a } 15 \text { min time step }\end{array}$ \\
\hline $\mathrm{H}_{2} \mathrm{O}$ emission & $\mathrm{kg}$ & $1.25 \times 10^{7}$ & Takes place during a 15 min time step \\
\hline Overall propulsion efficiency & - & 0.31 & See Schumann (2000) \\
\hline $\mathrm{H}_{2} \mathrm{O}$ emission index & $\operatorname{kg}\left(\mathrm{H}_{2} \mathrm{O}\right)(\mathrm{kg}(\text { fuel }))^{-1}$ & 1.25 & Schumann (2000) \\
\hline Kerosene combustion heat & $\mathrm{Jkg}^{-1}$ & $43.2 \times 10^{6}$ & Schumann (2000) \\
\hline
\end{tabular}

over the 24 time-region grid points at different locations. While the mean standard deviation of the results is almost $20 \%$ for $\mathrm{NO}_{\mathrm{x}}$ and $12 \%$ for ozone when using only 2 air parcel trajectories, it drops quickly with an increasing number of air parcel trajectories and both the mean values and the extremes lie below $10 \%$ for more than 20 air parcel trajectories. Thus, this analysis suggests that the potential error in the results for $\mathrm{NO}_{\mathrm{x}}$ and ozone almost converged for 50 air parcel trajectories and is lower than $10 \%$ if 20 or more air parcel trajectories are used.

\subsubsection{Sensitivity to temporal and horizontal resolution}

We have tested the impact of the temporal and horizontal resolution of the time-region grid on the climate cost functions. For the test of the temporal resolution, we included an emission time at 09:00 UTC in addition to the standard emission times at 06:00 UTC and 12:00 UTC at $250 \mathrm{hPa}$ and between $45^{\circ} \mathrm{N}$ and $50^{\circ} \mathrm{N}$. The interpolated values are compared to the simulated 09:00 UTC values. The $\mathrm{NO}_{\mathrm{x}}$ and ozone masses vary by roughly $\pm 40 \%$ and $\pm 25 \%$.

Concerning the horizontal resolution we have added emission locations in between the chosen grid, i.e. a latitudinal shift of $2.5^{\circ}$ and longitudinal shift of $7.5^{\circ}$ at $250 \mathrm{hPa}$ and 12:00 UTC. The results show a variability of the order of $50 \%$ and $35 \%$ for $\mathrm{NO}_{\mathrm{x}}$ and ozone, respectively.

Hence the horizontal interpolation is more critical than the temporal interpolation. The intercomparison further shows that the resolution of the climate cost function is crucial to the optimisation of the air traffic system with respect to its climate impact. However, the variation of the climate impact from $\mathrm{NO}_{\mathrm{x}}$ emissions varies by one order of magnitude and is hence larger than the possible interpolation error.

\subsection{Atmospheric changes}

\subsubsection{Chemistry: $\mathrm{NO}_{\mathrm{x}}, \mathrm{O}_{3}(+\mathrm{PMO}), \mathrm{OH}, \mathrm{CH}_{4}$}

We consider a $\mathrm{NO}_{\mathrm{x}}$ emission of $5 \times 10^{5} \mathrm{~kg}$ for each timeregion grid point. This influences ozone production and loss as well as the $\mathrm{HO}_{\mathrm{x}}$ partitioning and hence methane loss.

From the detailed modelling in EMAC, we obtain relevant production $(\mathrm{P})$ and loss $(\mathrm{L})$ terms. Those terms are then used in the following tagging approach. A prerequisite of this tagging approach is a complete and disjunct partitioning of the emissions into categories. Here we consider two emission categories, a background (b) and the additional emission (e) for calculation of the climate cost function. For this emission category e the contribution of this category to the ozone production via the reaction

$\mathrm{HO}_{2}+\mathrm{NO} \longrightarrow \mathrm{OH}+\mathrm{NO}_{2}$

is calculated (according to Grewe et al., 2010):

$P_{\mathrm{O}_{3}}^{\mathrm{e}}=P_{\mathrm{O}_{3}}^{\mathrm{b}} \cdot \frac{1}{2}\left(\frac{\mathrm{HO}_{2}^{\mathrm{e}}}{\mathrm{HO}_{2}^{\mathrm{b}}}+\frac{\mathrm{NO}^{\mathrm{e}}}{\mathrm{NO}^{\mathrm{b}}}\right)$,

where the superscripts $\mathrm{b}$ and $\mathrm{e}$ indicate background values and values specific for the tagged emission category, respectively. $P_{\mathrm{O}_{3}}$ denotes the ozone production rate in $\left[\mathrm{mol} \mathrm{mol}^{-1} \mathrm{~s}^{-1}\right]$. All species are given in mixing ratios $\left[\mathrm{mol} \mathrm{mol}^{-1}\right]$. The reaction rate for loss terms of tagged species is determined in the same manner, e.g. for the reaction

$\mathrm{NO}_{2}+\mathrm{O}_{3} \longrightarrow \mathrm{NO}+2 \mathrm{O}_{2}$

the loss term $L_{\mathrm{O}_{3}}^{\mathrm{e}}$ is

$L_{\mathrm{O}_{3}}^{\mathrm{e}}=L_{\mathrm{O}_{3}}^{\mathrm{b}} \cdot \frac{1}{2}\left(\frac{\mathrm{NO}_{2}^{\mathrm{e}}}{\mathrm{NO}_{2}^{\mathrm{b}}}+\frac{\mathrm{O}_{3}^{\mathrm{e}}}{\mathrm{O}_{3}^{\mathrm{b}}}\right)$.

Note that the first term in brackets includes the loss of background ozone by $\mathrm{NO}_{2}^{\mathrm{e}}$ and that Eqs. (7) and (8) only represent the contributions from an emission e for the Reactions (R1) and (R2) without any further assumptions, e.g. without any linearisation of chemical processes.

For our approach we now introduce simplifications. First we combine background nitrogen species (all $\mathrm{N}$-compounds except $\mathrm{NO}, \mathrm{NO}_{2}$ and $\mathrm{HNO}_{3}$ ) to a family and calculate the contributions of time-region emissions according to this family concept, with the assumption that the emissions are small enough that the specific reaction rates are unchanged, i.e.

$\frac{P_{\mathrm{O}_{3}}^{\mathrm{b}}}{\mathrm{HO}_{2}^{\mathrm{b}} \cdot \mathrm{NO}^{\mathrm{b}}}=\frac{P_{\mathrm{O}_{3}}^{\mathrm{b}}+P_{\mathrm{O}_{3}}^{\mathrm{e}}}{\left(\mathrm{HO}_{2}^{\mathrm{b}}+\mathrm{HO}_{2}^{\mathrm{e}}\right)\left(\mathrm{NO}^{\mathrm{b}}+\mathrm{NO}^{\mathrm{e}}\right)}$.

Further, we regard the ozone production as primarily $\mathrm{NO}_{\mathrm{x}}-$ dependent and split the ozone destruction into two parts 

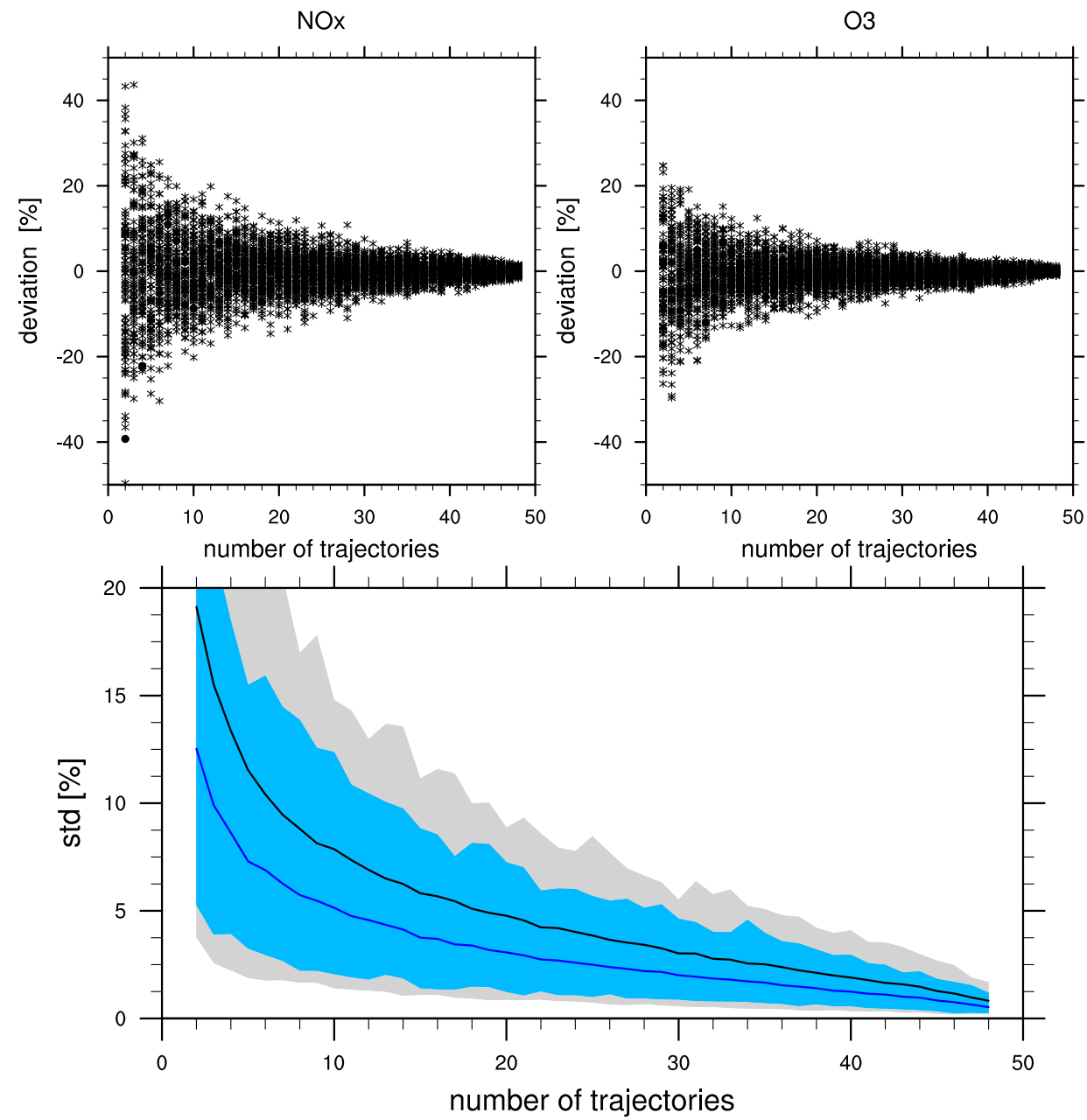

Fig. 6. Top: deviations [\%] of possible results of the monthly mean January $\mathrm{NO}_{\mathrm{x}}$ mixing ratio (left) and ozone mixing ratio (right) for emissions at $200 \mathrm{hPa}$ and $50^{\circ} \mathrm{N}, 45^{\circ} \mathrm{W}$ as a function of the number of air parcel trajectories simulated. The deviation is relative to the result using 50 air parcel trajectories. Bottom: standard deviations [\%] of the results for $\mathrm{NO}_{\mathrm{x}}$ and ozone shown as a function of the number of air parcel trajectories used for 24 different time-region grid points (shading: grey for $\mathrm{NO}_{\mathrm{x}}$ and blue for ozone) and the mean of the standard deviation over the 24 points (upper black line for $\mathrm{NO}_{\mathrm{x}}$, lower dark-blue line for ozone).

driven by two different chemical families: one based on $\mathrm{NO}_{\mathrm{x}}$, the other taking into account all other loss processes, which leads to the following differential equation for ozone:

$\frac{\mathrm{d}}{\mathrm{d} t} \mathrm{O}_{3}^{\mathrm{e}}=\frac{P_{\mathrm{O}_{3}}^{\mathrm{b}}}{\mathrm{NO}_{\mathrm{x}}^{\mathrm{b}}} \mathrm{NO}_{\mathrm{x}}^{\mathrm{e}}-\frac{1}{2} D_{\mathrm{O}_{3}, 1}^{\mathrm{b}}\left(\frac{\mathrm{NO}_{\mathrm{x}}^{\mathrm{e}}}{\mathrm{NO}_{\mathrm{x}}^{\mathrm{b}}}+\frac{\mathrm{O}_{3}^{\mathrm{e}}}{\mathrm{O}_{3}^{\mathrm{b}}}\right)-D_{\mathrm{O}_{3}, 2}^{\mathrm{b}} \frac{\mathrm{O}_{3}^{\mathrm{e}}}{\mathrm{O}_{3}^{\mathrm{b}}}$

This implicitly includes the assumption that the NO-to$\mathrm{NO}_{2}$ ratio of the $\mathrm{NO}_{\mathrm{x}}$ emitted in the time region is equal to the ratio of the background $\mathrm{NO}_{\mathrm{x}}$. After $\mathrm{NO}_{\mathrm{x}}$ is emitted, we take into account an exchange with $\mathrm{HNO}_{3}^{\mathrm{e}}$, which will eventually be washed out.

Figure 7 shows the evolution of the contributions to the atmospheric burden $[\mathrm{kg}]$ of various species as an example for an emission at $200 \mathrm{hPa}, 30^{\circ} \mathrm{N}$ and $75^{\circ} \mathrm{W}$. Nitrogen oxides are completely washed out within a month. Ozone increases as long as enough $\mathrm{NO}_{\mathrm{x}}$ molecules are available and is subsequently destroyed when this is no longer the case.

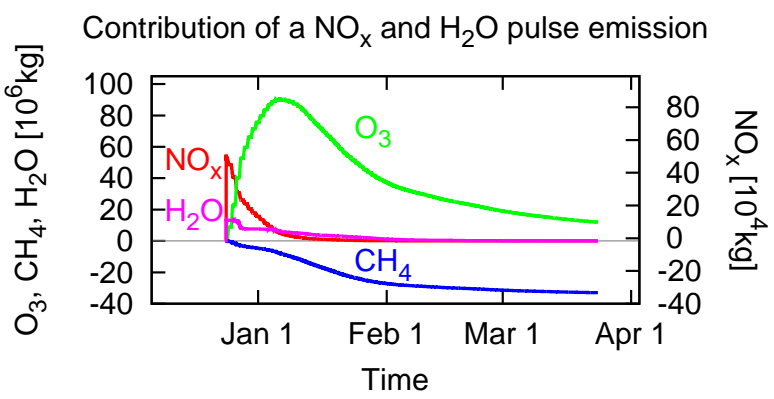

Fig. 7. Contributions from $\mathrm{NO}_{\mathrm{x}}$ and $\mathrm{H}_{2} \mathrm{O}$ emissions in a time region (here: $75^{\circ} \mathrm{W}, 30^{\circ} \mathrm{N} ; 200 \mathrm{hPa} ; 23$ December, 06:00 UTC) to $\mathrm{NO}_{\mathrm{x}}$ (red), ozone (green), methane (blue) and water vapour (magenta) global atmospheric masses [kg]. 
An analogous approach is used for methane. We take into account the most relevant reactions regarding the concentration of $\mathrm{OH}$ and $\mathrm{HO}_{2}$ :

Production of $\mathrm{OH}$ :

$$
\begin{aligned}
\mathrm{H}_{2} \mathrm{O}+\mathrm{O}\left({ }^{1} \mathrm{D}\right) & \longrightarrow 2 \mathrm{OH} \\
\mathrm{HO}_{2}+\mathrm{O}_{3} & \longrightarrow \mathrm{OH}+2 \mathrm{O}_{2} \\
\mathrm{HO}_{2}+\mathrm{NO} & \longrightarrow \mathrm{OH}+\mathrm{NO}_{2} .
\end{aligned}
$$

Loss of $\mathrm{OH}$ :

$$
\begin{gathered}
\mathrm{OH}+\mathrm{O}_{3} \longrightarrow \mathrm{HO}_{2}+\mathrm{O}_{2} \\
\mathrm{OH}+\mathrm{CO} \stackrel{\mathrm{O}_{2}}{\longrightarrow} \mathrm{HO}_{2}+\mathrm{CO}_{2} \\
\mathrm{OH}+\mathrm{RH} \stackrel{\mathrm{O}_{2}}{\longrightarrow} \mathrm{RO}_{2}+\mathrm{H}_{2} \mathrm{O} \\
\mathrm{OH}+\mathrm{CH}_{4} \stackrel{\mathrm{O}_{2}}{\longrightarrow} \mathrm{CH}_{3} \mathrm{O}_{2}+\mathrm{H}_{2} \mathrm{O} \\
\mathrm{OH}+\mathrm{HO}_{2} \longrightarrow \mathrm{H}_{2} \mathrm{O}+\mathrm{O}_{2} .
\end{gathered}
$$

Production of $\mathrm{HO}_{2}$ in addition to Reactions (R6) and (R7):

$\mathrm{RO}_{2}+\mathrm{NO} \stackrel{\mathrm{O}_{2}}{\longrightarrow} \mathrm{HO}_{2}+\mathrm{R}^{\prime} \mathrm{CHO}+\mathrm{NO}_{2}$

Loss of $\mathrm{HO}_{2}$ in addition to Reactions (R4), (R5) and (R10):

$$
\begin{aligned}
& \mathrm{RO}_{2}+\mathrm{HO}_{2} \longrightarrow \mathrm{ROOH}+\mathrm{O}_{2} \\
& \mathrm{HO}_{2}+\mathrm{HO}_{2} \longrightarrow \mathrm{H}_{2} \mathrm{O}_{2}+\mathrm{O}_{2} .
\end{aligned}
$$

We are not considering aircraft contributions for $\mathrm{H}_{2} \mathrm{O}, \mathrm{CO}$, $\mathrm{RH}$ and $\mathrm{CH}_{4}$ for this approach, since their effects on $\mathrm{OH}$ are considered to be small. The production and loss of $\mathrm{OH}^{\mathrm{e}}$, i.e. $\mathrm{OH}$ of the respective emission category, follow in analogy to Eq. (7):

$$
\begin{aligned}
P_{\mathrm{OH}}^{\mathrm{e}}= & P_{\mathrm{R} 3}^{\mathrm{b}} \frac{\mathrm{O}_{3}^{\mathrm{e}}}{\mathrm{O}_{3}^{\mathrm{b}}}+\frac{1}{2} P_{\mathrm{R} 4}^{\mathrm{b}}\left(\frac{\mathrm{HO}_{2}^{\mathrm{e}}}{\mathrm{HO}_{2}^{\mathrm{b}}}+\frac{\mathrm{O}_{3}^{\mathrm{e}}}{\mathrm{O}_{3}^{\mathrm{b}}}\right) \\
& +\frac{1}{2} P_{\mathrm{R} 5}^{\mathrm{b}}\left(\frac{\mathrm{HO}_{2}^{\mathrm{e}}}{\mathrm{HO}_{2}^{\mathrm{b}}}+\frac{\mathrm{NO}_{\mathrm{x}}^{\mathrm{e}}}{\mathrm{NO}_{\mathrm{x}}^{\mathrm{b}}}\right)
\end{aligned}
$$

and

$$
\begin{aligned}
L_{\mathrm{OH}}^{\mathrm{e}}= & \frac{1}{2} L_{\mathrm{R} 6}^{\mathrm{b}}\left(\frac{\mathrm{OH}^{\mathrm{e}}}{\mathrm{OH}^{\mathrm{b}}}+\frac{\mathrm{O}_{3}^{\mathrm{e}}}{\mathrm{O}_{3}^{\mathrm{b}}}\right) \\
& +L_{\mathrm{R} 7}^{\mathrm{b}} \frac{\mathrm{OH}^{\mathrm{e}}}{\mathrm{OH}^{\mathrm{b}}}+L_{\mathrm{R} 8}^{\mathrm{b}} \frac{\mathrm{OH}^{\mathrm{e}}}{\mathrm{OH}^{\mathrm{b}}}+L_{\mathrm{R} 9}^{\mathrm{b}} \frac{\mathrm{OH}^{\mathrm{e}}}{\mathrm{OH}^{\mathrm{b}}} \\
& +\frac{1}{2} L_{\mathrm{R} 10}^{\mathrm{b}}\left(\frac{\mathrm{OH}^{\mathrm{e}}}{\mathrm{OH}^{\mathrm{b}}}+\frac{\mathrm{HO}_{2}^{\mathrm{e}}}{\mathrm{HO}_{2}^{\mathrm{b}}}\right) .
\end{aligned}
$$

In an analogous way, we derive the production and loss terms for $\mathrm{HO}_{2}^{\mathrm{e}}$ and obtain differential equations for $\mathrm{OH}^{\mathrm{e}}$ and
$\mathrm{HO}_{2}^{\mathrm{e}}$, which easily can be solved as follows:

$$
\begin{aligned}
\frac{\mathrm{d}}{\mathrm{d} t} \mathrm{OH}^{\mathrm{e}} & =P_{\mathrm{OH}}^{\mathrm{e}}-L_{\mathrm{OH}}^{\mathrm{e}} \\
& =A_{0}+A_{1} \frac{\mathrm{HO}_{2}^{\mathrm{e}}}{\mathrm{HO}_{2}^{\mathrm{b}}}+A_{2} \frac{\mathrm{OH}^{\mathrm{e}}}{\mathrm{OH}^{\mathrm{b}}} \\
& =0 \\
\frac{\mathrm{d}}{\mathrm{d} t} \mathrm{HO}_{2}^{\mathrm{e}} & =P_{\mathrm{HO}_{2}}^{\mathrm{e}}-L_{\mathrm{HO}_{2}}^{\mathrm{e}} \\
& =B_{0}+B_{1} \frac{\mathrm{HO}_{2}^{\mathrm{e}}}{\mathrm{HO}_{2}^{\mathrm{b}}}+B_{2} \frac{\mathrm{OH}^{\mathrm{e}}}{\mathrm{OH}^{\mathrm{b}}} \\
& =0 \\
\mathrm{OH}^{\mathrm{e}} & =\mathrm{OH}^{\mathrm{b}} \frac{A_{0} B_{1}-A_{1} B_{0}}{A_{1} B_{2}-A_{2} B_{1}} \\
\mathrm{HO}_{2}^{\mathrm{e}} & =\mathrm{HO}_{2}^{\mathrm{b}} \frac{A_{2} B_{0}-A_{0} B_{2}}{A_{1} B_{2}-A_{2} B_{1}}
\end{aligned}
$$

with

$$
\begin{aligned}
& A_{0}=\left(P_{\mathrm{R} 3}^{\mathrm{b}}+\frac{1}{2} P_{\mathrm{R} 4}^{\mathrm{b}}-\frac{1}{2} L_{\mathrm{R} 6}^{\mathrm{b}}\right) \frac{\mathrm{O}_{3}^{\mathrm{e}}}{\mathrm{O}_{3}^{\mathrm{b}}}+\frac{1}{2} P_{\mathrm{R} 5}^{\mathrm{b}} \frac{\mathrm{NO}_{\mathrm{x}}^{\mathrm{e}}}{\mathrm{NO}_{\mathrm{x}}^{\mathrm{b}}} \\
& A_{1}=\frac{1}{2}\left(P_{\mathrm{R} 4}^{\mathrm{b}}+P_{\mathrm{R} 5}^{\mathrm{b}}-L_{\mathrm{R} 10}^{\mathrm{b}}\right) \\
& A_{2}=-\frac{1}{2} L_{\mathrm{R} 6}^{\mathrm{b}}-L_{\mathrm{R} 7}^{\mathrm{b}}-L_{\mathrm{R} 8}^{\mathrm{b}}-L_{\mathrm{R} 9}^{\mathrm{b}}-\frac{1}{2} L_{\mathrm{R} 10}^{\mathrm{b}} \\
& B_{0}=\frac{1}{2}\left(L_{\mathrm{R} 6}^{\mathrm{b}}-P_{\mathrm{R} 4}^{\mathrm{b}}\right) \frac{\mathrm{O}_{3}^{\mathrm{e}}}{\mathrm{O}_{3}^{\mathrm{b}}}+\left(P_{\mathrm{R} 11}^{\mathrm{b}}-\frac{1}{2} P_{\mathrm{R} 5}^{\mathrm{b}}\right) \frac{\mathrm{NO}_{\mathrm{x}}^{\mathrm{e}}}{\mathrm{NO}_{\mathrm{x}}^{\mathrm{b}}} \\
& B_{1}=-\frac{1}{2} P_{\mathrm{R} 4}^{\mathrm{b}}-\frac{1}{2} P_{\mathrm{R} 5}^{\mathrm{b}}-\frac{1}{2} L_{\mathrm{R} 10}^{\mathrm{b}}-P_{\mathrm{R} 12}^{\mathrm{b}}-P_{\mathrm{R} 13}^{\mathrm{b}} \\
& B_{2}=\frac{1}{2} L_{\mathrm{R} 6}^{\mathrm{b}}+L_{\mathrm{R} 7}^{\mathrm{b}}-\frac{1}{2} L_{\mathrm{R} 10}^{\mathrm{b}} .
\end{aligned}
$$

The methane loss caused by the contribution of aircraft emissions to the $\mathrm{OH}$ concentration is then

$$
\begin{aligned}
L_{\mathrm{CH}_{4}}^{\mathrm{e}} & =L_{\mathrm{R} 9}^{\mathrm{b}} \frac{\mathrm{OH}^{\mathrm{e}}}{\mathrm{OH}^{\mathrm{b}}} \\
& =L_{\mathrm{R} 9}^{\mathrm{b}} \frac{A_{0} B_{1}-A_{1} B_{0}}{A_{1} B_{2}-A_{2} B_{1}} .
\end{aligned}
$$

Figure 7 shows, in addition to $\mathrm{NO}_{\mathrm{x}}$ and $\mathrm{O}_{3}$, the evolution for methane. Methane decreases first because of an increase in $\mathrm{OH}$ via Reaction $(\mathrm{R} 1)$. When $\mathrm{NO}_{\mathrm{x}}$ is removed from the atmosphere, the increase in ozone concentrations leads to an enhanced methane reduction.

\subsubsection{Aircraft-induced cloudiness}

Contrails form in the atmosphere when the ambient air at flight levels is sufficiently cold and moist (SchmidtAppleman criterion, SAC; Schumann, 1996). Once formed, contrails may persist if the air is supersaturated relative to ice and evolve into contrail cirrus, i.e. they lose their line-shaped structure. Here we generally refer to contrails and do not distinguish between line-shaped contrails and contrail cirrus. 
We determine the atmospheric ability to form persistent contrails, i.e. the potential contrail coverage, instantaneously within the climate model at each time step following the approach of Burkhardt et al. (2008) and Burkhardt and Kärcher (2009). The potential contrail coverage, $b_{\text {co }}$, is the fraction of an EMAC grid box which can be maximally covered by contrails. It is calculated as the difference between the maximum possible coverage of both contrails and cirrus $\left(b_{\mathrm{co}+\mathrm{ci}}\right)$, and the coverage of natural cirrus alone $\left(b_{\mathrm{ci}}\right)$ :

$b_{\mathrm{co}}=b_{\mathrm{co}+\mathrm{ci}}-b_{\mathrm{ci}}, \quad$ with

$b_{\mathrm{ci}}=1-\sqrt{\frac{r-r_{\mathrm{ci}}}{r_{\mathrm{sat}}-r_{\mathrm{ci}}}}$, and

$b_{\mathrm{co}+\mathrm{ci}}= \begin{cases}\frac{r-r_{\mathrm{co}}}{r_{\mathrm{sat}}-r_{\mathrm{ci}}}-b_{\mathrm{ci}}\left(1-b_{\mathrm{ci}}\right) & \text { for } r_{\mathrm{co}} \leq r \leq r^{*} \\ 1 & \text { for } r>r^{*} .\end{cases}$

Here, $r$ denotes the EMAC grid mean relative humidity. $r_{\mathrm{ci}}$ and $r_{\mathrm{co}}$ are critical relative humidities above which a fraction of the EMAC grid box is covered by cirrus and is ice-supersaturated, respectively; $r_{\text {sat }}=1$ is the relative humidity at saturation. The relative humidity $r^{*}=r_{\mathrm{sat}}-\left(r_{\mathrm{ci}}-\right.$ $\left.r_{\mathrm{co}}\right)^{2} /\left(r_{\text {sat }}-r_{\mathrm{ci}}\right)$ (see Burkhardt et al., 2008, and supplementary material therein).

The critical relative humidity for contrail formation, $r_{\mathrm{co}}$, is calculated via

$\frac{r_{\mathrm{co}}}{r_{\mathrm{ci}}}=\frac{r_{\mathrm{SAC}}}{a r_{\mathrm{nuc}}}$,

with $r_{\mathrm{SAC}}$ being the relative humidity over ice at which the Schmidt-Appleman criterion is fulfilled during the mixing of aircraft exhaust gases and ambient air, and $r_{\text {nuc }}$ being the homogeneous freezing threshold. As contrails often form prior to the formation of natural cirrus $a=0.9$ is chosen (following Burkhardt et al., 2008).

The potential contrail coverage is transferred to the air parcel trajectories. Then the actual contrail coverage is calculated depending on whether air traffic is actually taking place in the respective EMAC grid box. Further physical processes such as contrail spreading, sedimentation of ice particles, water uptake and sublimation are parameterised. Contrails are described by their coverage $(b)$ and water mixing ratio $(m)$.

The prognostic equation for the contrail coverage is the sum of newly formed contrails and the spreading of preexisting ones:

$\frac{\mathrm{d} b}{\mathrm{~d} t}=\left(\frac{\mathrm{d} b}{\mathrm{~d} t}\right)_{\text {new }}+\left(\frac{\mathrm{d} b}{\mathrm{~d} t}\right)_{\text {spread }}$,

with the following boundary conditions that the resulting contrail coverage $b$ fulfils:

$b \leq b_{\text {co }}$

$b=0$ for $m<m_{\text {thres }}$.

The newly formed contrails cover an area according to the initial contrail dimensions, such as the width $W_{0}$ and the length of the contrail in the EMAC grid box ( $D$; see also Table 4). We assume a flown distance

$D=\sqrt{A}, \quad$ and hence an initial contrail length of

$L=D b_{\mathrm{co}}$,

where $A$ is the gridbox area. The resulting new contrail coverage tendency is then

$\left(\frac{\mathrm{d} b}{\mathrm{~d} t}\right)_{\text {new }}=\frac{W_{0} L}{A \Delta t}=\frac{W_{0} b_{\mathrm{co}}}{\sqrt{A} \Delta t}$.

The spreading of the contrails is parameterised according to Burkhardt and Kärcher (2009) depending on the vertical wind shear:

$\left(\frac{\mathrm{d} b}{\mathrm{~d} t}\right)_{\text {spread }}=c \sqrt{\left(\frac{\partial u}{\partial z}\right)^{2}+\left(\frac{\partial v}{\partial z}\right)^{2}} \frac{H L}{A}$.

The prognostic equation for the contrail ice mass mixing ratio $m$ includes the formation of new contrails, sedimentation (or precipitation) of ice mass, deposition of water vapour on the contrail ice particles, and sublimation (Burkhardt and Kärcher, 2009):

$\frac{\mathrm{d} m}{\mathrm{~d} t}=\left(\frac{\mathrm{d} m}{\mathrm{~d} t}\right)_{\text {new }}+\left(\frac{\mathrm{d} m}{\mathrm{~d} t}\right)_{\text {sed }}+\left(\frac{\mathrm{d} m}{\mathrm{~d} t}\right)_{\mathrm{dep} / \text { subl }}$.

Similar to Ponater et al. (2002) we assume that the newly formed contrail ice water mixing ratio depends on the condensation rate in the contrail-covered part of the EMAC grid box $c_{\text {co }}$, which is defined analogously to the condensation rate for natural clouds $c_{\mathrm{cl}}$ :

$\left(\frac{\mathrm{d} m}{\mathrm{~d} t}\right)_{\text {new }}=c_{\mathrm{cl}}$

Extending over Ponater et al. (2002), however, contrail ice is also subject to physical sinks: the sedimentation rate of ice particles in the contrail is parameterised according to Heymsfield and Donner (1990) based on the vertical divergence of the flux of ice particles $F$ in $\left[\mathrm{kg} \mathrm{m}^{-2} \mathrm{~s}^{-1}\right]$ :

$\left(\frac{\mathrm{d} m}{\mathrm{~d} t}\right)_{\mathrm{sed}}=\frac{1}{\rho} \frac{\mathrm{d} F}{\mathrm{~d} z}, F=v m \rho, v=\alpha(\rho m)^{\beta}$,

where $v$ is the falling velocity $\left[\mathrm{ms}^{-1}\right]$ of ice particles, which are parameterised with $\alpha=3.29$ and $\beta=0.16$, and $\rho$ is the air density in $\left[\mathrm{kg} \mathrm{m}^{-3}\right]$.

The sublimation and growth is parameterised according to a relative decrease or an increase of the potential contrail coverage, resulting from a decrease or increase of the relative humidity, respectively:

$\left(\frac{\mathrm{d} m}{\mathrm{~d} t}\right)_{\mathrm{dep} / \mathrm{subl}}=\frac{1}{b_{\mathrm{co}}} \frac{\mathrm{d} b_{\mathrm{co}}}{\mathrm{d} t} m=\frac{\mathrm{d} \ln b_{\mathrm{co}}}{\mathrm{d} t} m$.

Note that the potential contrail coverage is available at a higher resolution than the RF calculated on the time-region 
Table 4. Parameters of the contrail parameterisation.

\begin{tabular}{llll}
\hline Parameter & Value & Unit & Description \\
\hline$W_{0}$ & 200 & $\mathrm{~m}$ & Initial contrail width \\
$A$ & variable & $\mathrm{m}^{2}$ & EMAC grid box area \\
$D$ & $\sqrt{A}$ & $\mathrm{~m}$ & Flown distance in the EMAC grid box \\
$L$ & $D b_{\mathrm{co}}$ & $\mathrm{m}$ & Initial contrail length \\
$\Delta t$ & 900 & $\mathrm{~s}$ & Time step (15 min) \\
$H$ & 200 & $\mathrm{~m}$ & Initial contrail thickness \\
$c$ & 0.72 & - & Scaling factor for contrail spreading \\
$m_{\text {thres }}$ & $10^{-10}$ & $\mathrm{~kg} \mathrm{~kg}$ & Water vapour mixing ratio \\
& & & threshold for contrail coverage \\
\hline
\end{tabular}

grid points. This information is used after the mapping from the lower resolution of the time-region grid to the higher resolution EMAC and CCF grid (Fig. 3) to ensure that contrail climate cost functions differ from zero only where contrails form in EMAC.

\subsection{3 $\quad \mathrm{H}_{2} \mathrm{O}$ and $\mathrm{CO}_{2}$}

For every time region, a water vapour emission is taken into account (Table 3$)$. This emitted water vapour $\left(\mathrm{H}_{2} \mathrm{O}\right.$ in $\left[\mathrm{mol} \mathrm{mol}^{-1}\right]$ ) is transported via Lagrangian transport, like the other tracers. Only loss processes are considered:

$$
\frac{\mathrm{dH}_{2} \mathrm{O}}{\mathrm{d} t}=-\frac{\mathrm{pr}}{\mathrm{H}_{2} \mathrm{O}^{\mathrm{tot}}} \mathrm{H}_{2} \mathrm{O}
$$

where $\mathrm{pr}$ is the precipitation rate, i.e. the water vapour loss in $\left[\mathrm{mol} \mathrm{mol}{ }^{-1} \mathrm{~s}^{-1}\right]$ in the respective EMAC gridbox due to rain and snowfall, and $\mathrm{H}_{2} \mathrm{O}^{\text {tot }}$ is the respective EMAC grid box total water vapour in $\left[\mathrm{mol} \mathrm{mol}{ }^{-1}\right]$.

Carbon dioxide emissions are assumed to lead to a wellmixed enhancement of the carbon dioxide mixing ratio because of its long perturbation life time. The temporal evolution of the concentration change (decay) is given for a unit of fuel used $\mathrm{CO}_{2}(t)$ in $\left[\mathrm{kg}\left(\mathrm{CO}_{2}\right)(\mathrm{kg}(\text { fuel }))^{-1}\right]$ following $\mathrm{Fu}$ glestvedt et al. (2010) and Forster et al. (2007):

$\mathrm{CO}_{2}(t)=\mathrm{EI}_{\mathrm{CO}_{2}} \sum_{i=0}^{3} a_{i} e^{-\frac{t}{\alpha_{i}}}$

(see Table 5 for details).

\subsection{Radiative forcing}

Table 6 gives an overview on the RF calculation for the individual species. The RF calculation for $\mathrm{CO}_{2}$ is based on Fuglestvedt et al. (2010) and includes a simple linearised conversion factor between the change in its atmospheric mass and the RF of $1.82 \times 10^{-12} \mathrm{~mW} \mathrm{~m}^{-2}\left(\mathrm{~kg}\left(\mathrm{CO}_{2}\right)\right)^{-1}$. The contrail RF is derived from the global mean radiation flux changes $F$ at the tropopause:

$\mathrm{RF}^{\text {contrail }}=\frac{1}{T} \int_{t_{0}}^{t_{0}+T} F(t) \mathrm{d} t$,

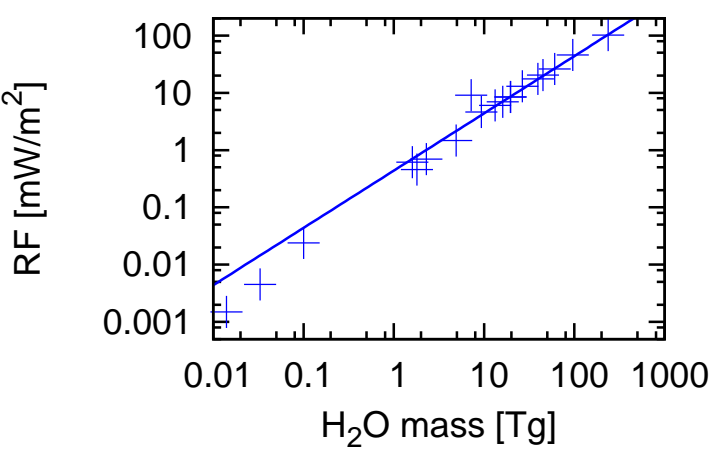

Fig. 8. Relation between change in atmospheric water vapour $[\mathrm{Tg}]$ and adjusted radiative forcing $\left[\mathrm{mW} \mathrm{m}^{-2}\right]$ for a fixed emission at different locations. Note that this relation is only valid if a constant emission is taken at different locations, which results in both different mass changes and different RFs. Data are from Grewe and Stenke (2008). The line represents a fit with $\mathrm{RF}=$ $4.38 \times 10^{-13} \mathrm{~W} \mathrm{~m}^{-2} \mathrm{~kg}^{-1}$.

where $T=1 \mathrm{yr}$.

Ozone RF is calculated analogously, except that the instantaneous RF is converted into the adjusted RF (details are described in the Appendix) via an analytical formula:

$\mathrm{RF}_{\mathrm{adj}}=f_{1}(t) \times f_{2}(p) \times \mathrm{RF}_{\text {inst }}$.

The unitless functions $f_{1}$ and $f_{2}$ describe the relation between $\mathrm{RF}_{\mathrm{adj}}$ and $\mathrm{RF}_{\mathrm{inst}}$ for various times of the year $\left(f_{1}\right.$, seasonal cycle) and various perturbation altitudes $\left(f_{2}\right)$ and are derived from additional idealised simulations.

Methane RF is derived from the methane mass changes calculated explicitly (Sect. 3.3.1) by applying the respective IPCC formula (Shine et al., 1990). PMO radiative forcing is derived from the methane radiative forcing by a constant factor of 0.29 (Dahlmann, 2012). Water-vapour-adjusted RF is calculated based on results from Grewe and Stenke (2008, see Fig. 8). Grewe and Stenke (2008) investigated the consequences of sustained water vapour emissions at different atmospheric locations between the surface and $50 \mathrm{hPa}$ and between the North Pole and the tropics. The results show that the adjusted RF depends on the lifetime of the perturbation and a linear relationship between the resulting atmospheric mass change and RF (Fig. 8). Note that Fig. 8 does not show a direct correlation between the water vapour mass changes and the RF, but does show that a given emission leads to a change in both the atmospheric mass and a RF, which both depend on the location where the emission takes place. Here, we have the same assumption, which is a constant emission at different locations (i.e. time-region grid points) and calculate the mass change explicitly (Sect. 3.3.3) so that we can use the mass-RF relationship (Fig. 8). 
Table 5. Parameters of the $\mathrm{CO}_{2}$ parameterisation.

\begin{tabular}{llll}
\hline Parameter & Value & Unit & Description \\
\hline $\mathrm{EI}_{\mathrm{CO}_{2}}$ & 3.16 & $\mathrm{~kg}\left(\mathrm{CO}_{2}\right)(\mathrm{kg}(\text { fuel }))^{-1}$ & $\mathrm{CO}_{2}$ emission index \\
$a_{i}$ & $0.217 ; 0.259 ; 0.388 ; 0.186$ & - & Weighting factors \\
$\alpha_{i}$ & $\infty ; 172.9 ; 18.51 ; 1.186$ & $\mathrm{yr}$ & Lifetime \\
\hline
\end{tabular}

Table 6. Overview on radiative forcing calculation for various species. "A" and "I" stand for adjusted and instantaneous radiative forcing in the column "RF type".

\begin{tabular}{llll}
\hline Species & Concentration & RF type & Radiative forcing \\
\hline $\mathrm{CO}_{2}$ & Response formula (Eq. 47) & $\mathrm{A}$ & $\left.\left.1.82 \times 10^{-12} \mathrm{~mW} \mathrm{~m}^{-2} \mathrm{~kg}_{(\mathrm{CO}}\right)^{-1}\right)^{\mathrm{a}}$ \\
$\mathrm{O}_{3}$ & EMAC (Eq. 10) & $\mathrm{A}$ & EMAC \\
$\mathrm{CH}_{4}$ & EMAC (Eq. 30) & $\mathrm{A}$ & $\mathrm{IPCC}$ formula \\
$\mathrm{PMO}$ & - & $\mathrm{A}$ & $-0.29 \mathrm{RF}(\mathrm{PMO}) / \mathrm{RF}\left(\mathrm{CH}_{4}\right)^{\mathrm{c}}$ \\
$\mathrm{H}_{2} \mathrm{O}$ & EMAC & $\mathrm{A}$ & $\left.\left.4.38 \times 10^{-13} \mathrm{Wm}^{-2} \mathrm{~kg}_{2} \mathrm{H}_{2} \mathrm{O}\right)^{-1}\right)^{\mathrm{d}}$ \\
Contrails & EMAC & $\mathrm{I}$ & EMAC \\
\hline
\end{tabular}

${ }^{a}$ Fuglestvedt et al. (2010). ${ }^{b}$ Shine et al. (1990). ${ }^{c}$ Dahlmann (2012). ${ }^{d}$ Based on data from Grewe and Stenke (2008).

\subsection{Climate metrics and emission scenarios for the REACT4C objective}

We are aiming at minimising the air traffic's climate impact by alternative routings. However, the wording "climate impact" or "climate change" is not well defined and incorporates a variety of possible interpretations. Hence, we clarify our objectives and from that derive adequate climate metrics and emission scenarios (Grewe and Dahlmann, 2012). There is no uniquely applicable climate metric, so we implement several possible choices (climate objectives) in order to examine the implications on routing for each of them. Our approach differs only slightly from previous considerations, which stress the importance of choices on the emissions, metrics and time horizons (see e.g. Shine et al., 2005; Fuglestvedt et al., 2010). Here, we move the focus slightly: we spell out three political questions and group appropriate combinations of emissions, metrics and time horizons. Still, choices have to be made. The emissions, metrics and time horizons are those which are frequently used: pulse $(\mathrm{P})$, sustained (S) and future emission scenarios $(\mathrm{F})$; absolute global warming potential (AGWP); absolute global temperature potential (AGTP); and average temperature response (ATR) for time horizons of 20, 50, and $100 \mathrm{yr}$.

We aim at reducing the climate impact of air traffic by introducing a new routing strategy (more details in Sect. A2). That implies that this strategy is applied everyday for air traffic. We interpret climate change as the global mean temperature change. The definition of the strategy and the focus on global mean temperature change as a climate change indicator implies an emission scenario and a climate metric (see Table 7): the first question (Q1) is "what is the short-term climate impact of the REACT4C re-routing strategy?". The appropriate emission scenario is a best estimate for the future air traffic, and the average temperature response (ATR) for a $20 \mathrm{yr}$ time horizon, $H=20$, is a suitable climate indicator, which is abbreviated as F-ATR20 (Future emission-scenariobased Averaged Temperature Response on a $20 \mathrm{yr}$ time horizon):

$\operatorname{ATR} H=\frac{1}{H} \int_{t_{0}}^{t_{0}+H} \mathrm{~d} T(t) \mathrm{d} t$.

Since estimates of the future air traffic are naturally uncertain, one can argue that a sustained emission is an adequate assumption (abbreviated as S-ATR20). A third option is to replace the mean temperature change over the time horizon $H$ with the temperature change at the time horizon $H$, i.e. the absolute global temperature potential for sustained emissions (S-AGTP20) (see Supplement and Fuglestvedt et al., 2010). Furthermore, as a last option, with the assumption that the climate sensitivities are equal to $1 \mathrm{~K}\left(\mathrm{~W} \mathrm{~m}^{-2}\right)^{-1}$ for all species (see Eq. A1), the absolute global temperature potential for the time horizon $H=20$ can be approximated by the integrated radiative forcing for a pulse emission, i.e. PAGWP20.

The second objective, i.e. the second question $(\mathrm{Q} 2)$ is "what is the long-term climate impact of the REACT4C rerouting strategy?". This changes the focus from the near future to longer term effects, and hence, except for the time horizon $(H=100)$, the emission scenarios and metrics are the same as for $\mathrm{Q} 1$.

For reasons of completeness, we add here the third question (Q3): "what is the medium-range climate impact of a present-day REACT4C re-routing decision?". Here, a medium $(H=50)$ time horizon of $50 \mathrm{yr}$ is addressed, but 
Table 7. Overview of objectives and implied emission scenarios and climate metrics or indicators. "F", "S" and "P" indicate assumptions on emissions: future emission scenario, sustained emissions and pulse emissions, respectively. ATR is the average temperature response, AGTP the absolute global temperature potential, and AGWP the absolute global warming potential; the number after the metrics gives the time horizon in years.

\begin{tabular}{|c|c|c|c|c|c|}
\hline \multicolumn{2}{|c|}{$\begin{array}{l}\text { Q1: What is the short-term climate impact } \\
\text { of the REACT4C re-routing strategy? }\end{array}$} & \multicolumn{2}{|c|}{$\begin{array}{l}\text { Q2: What is the long-term climate impact } \\
\text { of the REACT4C re-routing strategy? }\end{array}$} & \multicolumn{2}{|c|}{$\begin{array}{l}\text { Q3: What is the medium-range climate impact } \\
\text { of a present-day REACT } 4 \mathrm{C} \text { re-routing decision? }\end{array}$} \\
\hline Emission & Metric & Emission & Metric & Emission & Metric \\
\hline Sustained emissions & S-ATR20 & Sustained emissions & S-ATR100 & Pulse emission & P-AGTP50 \\
\hline Sustained emissions & S-AGTP20 & Sustained emissions & S-AGTP100 & & \\
\hline Pulse emission & P-AGWP20 & Pulse emission & P-AGWP100 & & \\
\hline
\end{tabular}

Role of atmospheric processes

$\begin{array}{lll}\begin{array}{l}\text { Short-term atmospheric effects are } \\ \text { important }\end{array} & \begin{array}{l}\text { Short- and long-term atmospheric effects } \\ \text { are important }\end{array} & \begin{array}{l}\text { Long-term atmospheric effects are } \\ \text { important }\end{array} \\ \text { Focus on contrails and ozone } & \text { Focus on all species } & \text { Focus on carbon dioxide }\end{array}$

more importantly only the present-day routing change and not a change in the strategy is addressed. Hence a pulse emission in combination with ATR50 or AGTP50 are adequate choices of the combination of emission scenario and metrics.

The choice of the objective has a consequence on the importance of individual atmospheric processes (Table 7). From question Q1 to Q3 the focus shifts from short- to long-term effects and hence from contrails and ozone impacts to $\mathrm{CO}_{2}$ only. In order to restrict future analysis to both a minimum of metrics and a maximum in the range of uncertainties from the metrics, we suggest focusing on the metrics F-ATR20, FATR100, P-GWP20 and P-GWP100 in future applications.

\subsection{Summary on climate cost function calculation}

We have set up a modelling approach linking potential emissions at locally and temporarily confined regions to their climate impact, measured with climate metrics. This procedure follows previous approaches (e.g. IPCC, 1999; Grewe et al., 2007; Grewe and Stenke, 2008; Lee et al., 2010); however, it differs in some details, taking into account new findings. Table 1 shows the main features of this modelling chain. We used different grids (see also Fig. 3), starting from the grid of the base model EMAC, in which we included 504 selected time-region grid points which cover the North-Atlantic region. From the area immediately around each of the timeregion grid points, we started 50 air parcel trajectories each and allocated the resulting climate impact to this grid point. An interpolation to the original EMAC grid provides the final climate cost function grid. The impact of the interpolations and definition of the time-region grid is tested in Sect. 3.2 (see also Table 1).

Physical and chemical processes are calculated on the air parcel trajectories by extracting process information from the detailed EMAC model. The temporal evolution of chemical species, their lifetimes and relations between, for example, ozone and methane radiative forcing are analysed and compared to other studies in more detail in Sects. 4.1 and 4.2. The climate impact metrics are derived by standard formulas (see e.g. Fuglestvedt et al., 2010) and a sanity check given in Sect. 4.3. An overall evaluation of the metrics is given in Sect. 4.3 by intercomparing the P-AGWP20 metrics derived from this work with results obtained with the climate-chemistry response model AirClim (Grewe and Stenke, 2008; Grewe and Dahlmann, 2012).

\section{Verification}

We have set up a complex modelling scheme, combining new methods for calculating the contribution of aviation on atmospheric processes with an air traffic model. A validation of this specific model application is not possible, since most of the effects are not yet measured or are per se not measurable, such as the effect of a local $\mathrm{NO}_{\mathrm{x}}$ emission at $200 \mathrm{hPa}$ on the temperature change after $50 \mathrm{yr}$. Instead, we compare our results with earlier modelling studies. Even this is extremely difficult, since the focus of these studies is different and no direct intercomparison is possible. Hence we are more focusing on the soundness of the data (sanity check) rather than a verification or validation. An overview is given in Table 1.

The limited possibilities to directly compare the results of our modelling approach to either observational data or other model results emphasises the need to include sensitivity studies in future investigations on the changes in air traffic routing when optimising with respect to climate impact. This can be achieved by targeted manipulation of the climate cost functions with respect to, for example, the ratio of the impact from individual compounds, their variability or pattern and their consequences on the climate optimal routing changes. 

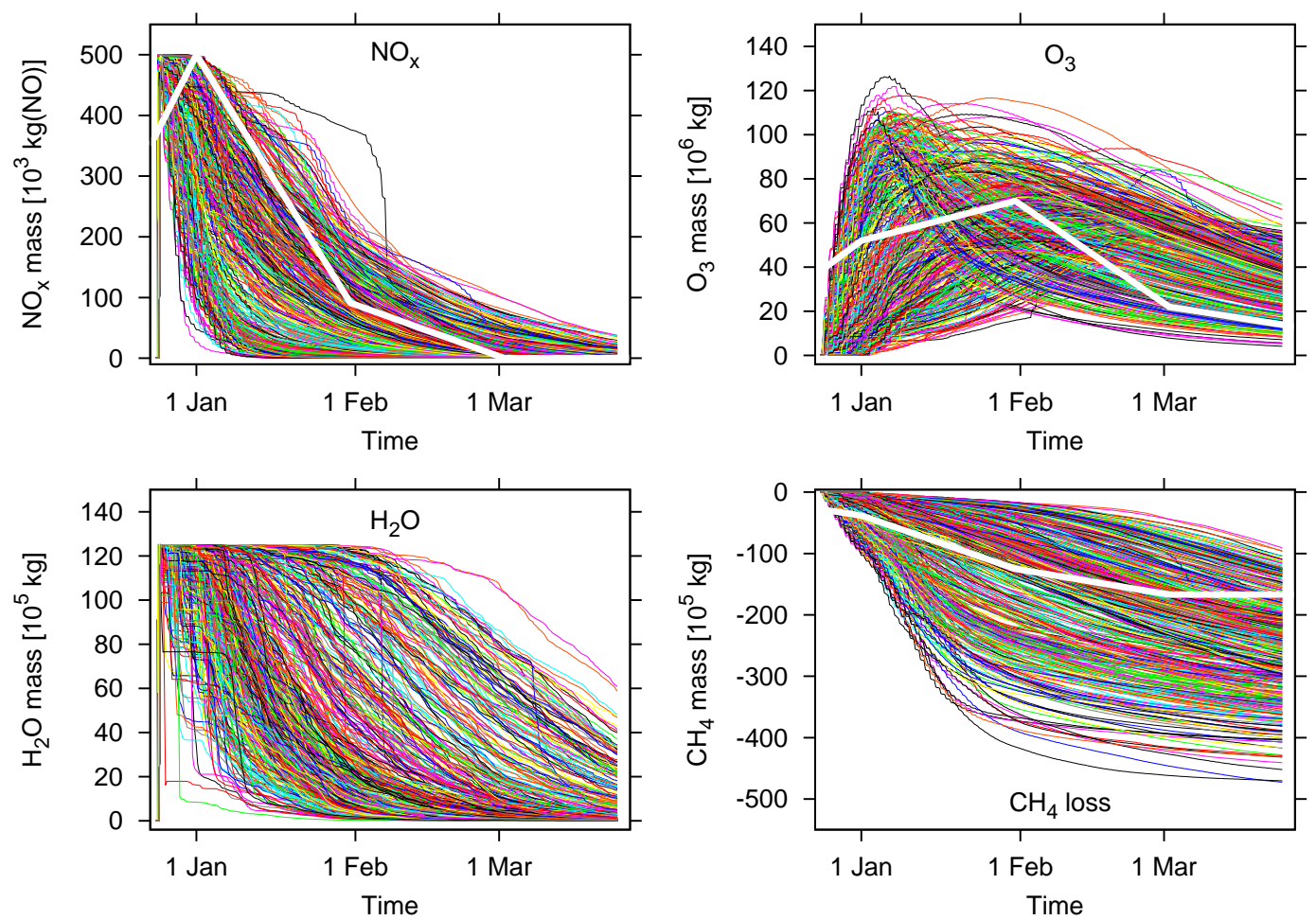

Fig. 9. Temporal evolution of global mean masses of $\mathrm{NO}_{\mathrm{x}}\left[10^{3} \mathrm{~kg}(\mathrm{NO})\right], \mathrm{O}_{3}\left[10^{6} \mathrm{~kg}\right], \mathrm{H}_{2} \mathrm{O}\left[10^{5} \mathrm{~kg}\right]$ and $\mathrm{CH}_{4}\left[10^{5} \mathrm{~kg}\right]$. For every timeregion grid point (see Table 2), 50 air parcel trajectories are started and the temporal evolution of the global mean over these 50 air parcel trajectories is presented; that is, each coloured line (in total 504) represents the temporal evolution of species caused by an emission at the respective time-region grid point. The white lines indicate results from Stevenson et al. (2004) scaled by the factor $6.94 \times 10^{-3}$ to derive the same initial $\mathrm{NO}_{\mathrm{x}}$ perturbation. Note that values by Stevenson et al. (2004) are monthly means.

\subsection{Chemistry}

We have computed climate cost functions for one specific day in December. The underlying weather pattern represents a strong zonal jet, which represents winter pattern 1 according to Irvine et al. (2013). For each cost function grid point (see Table 2), the mean over all 50 air parcel trajectories is calculated. Figure 9 shows the temporal development of $\mathrm{NO}_{\mathrm{x}}$, ozone and $\mathrm{H}_{2} \mathrm{O}$ as well as loss of $\mathrm{CH}_{4}$ of these mean values for each time-region grid point.

A $\mathrm{NO}_{\mathrm{x}}$ and ozone lifetime of $20 \pm 11$ days and $72 \pm$ 26 days, respectively, is calculated which is roughly in agreement with findings by Stevenson et al. (2004), who found a decrease of a $\mathrm{NO}_{\mathrm{x}}$ pulse emission from roughly $110 \mathrm{Gg}\left(\mathrm{NO}_{2}\right)$ to $20 \mathrm{Gg}\left(\mathrm{NO}_{2}\right)$ within a month, which represents a lifetime of approximately 25 days and a decrease of ozone from around $10 \mathrm{Tg}$ to $1.5 \mathrm{Tg}$ within 2 months, representing a lifetime of approximately 50 days (see also Fig. 9). The temporal evolution of $\mathrm{NO}_{\mathrm{x}}$, ozone and methane changes for a January pulse emission calculated by Stevenson et al. (2004) (white lines in Fig. 9) is well within the range of our results.
The relation between the $\mathrm{NO}_{\mathrm{x}}$ emission and ozone contribution as a mean over all time-region grid points is $7.8 \pm 2.4 \mathrm{DU}\left(\mathrm{TgNa}^{-1}\right)^{-1}$. Dahlmann et al. (2011), Frömming et al. (2012) and Grewe et al. (2002) calculated values for the whole air traffic and annual emissions of $1.4 \mathrm{DU}\left(\mathrm{TgN} \mathrm{a}^{-1}\right)^{-1}, 0.8 \mathrm{DU}\left(\mathrm{TgN} \mathrm{a}^{-1}\right)^{-1}$ and $0.7 \mathrm{DU}\left(\mathrm{TgN} \mathrm{a}^{-1}\right)^{-1}$, respectively. However, those studies consider a whole air traffic scenario, with a large contribution of emissions from lower altitudes and lower ozone impacts. In our study, the ratio between the $\mathrm{NO}_{\mathrm{x}}$ enhancement and the ozone change is $2400 \mathrm{~kg}\left(\mathrm{O}_{3}\right)$ per $\mathrm{kg}(\mathrm{N})$ with a range of 270 to $300000 \mathrm{~kg}\left(\mathrm{O}_{3}\right)$ per $\mathrm{kg}(\mathrm{N})$. Grewe et al. (2002) calculated a value of $300 \mathrm{~kg}\left(\mathrm{O}_{3}\right)$ per $\mathrm{kg}(\mathrm{N})$; thus our result is again at the lower end for the same reason. The respective $\mathrm{RF}$ value is $41 \mathrm{~mW} \mathrm{~m}^{-2} \mathrm{DU}^{-1}$ (this study) and compares well with $31 \mathrm{~mW} \mathrm{~m}^{-2} \mathrm{DU}^{-1}$ calculated by Dahlmann et al. (2011). The emission-specific ozone RF calculated here ranges from 15 to $2800 \mathrm{~mW} \mathrm{~m}^{-2} \mathrm{TgN}^{-1}$ with a mean value of $250 \mathrm{~mW} \mathrm{~m}^{-2} \mathrm{TgN}^{-1}$. Dahlmann et al. (2011) and Fuglestvedt et al. (2008) give mean values for the whole air traffic of $41 \mathrm{~mW} \mathrm{~m}^{-2} \mathrm{kgN}^{-1}$ and $45 \mathrm{~mW} \mathrm{~m}^{-2} \mathrm{kgN}^{-1}$, respectively, which are well within the simulated range. 
The relation between the ozone and methane RF is in the range of -0.5 to -1.3 . Lee et al. (2010) and Holmes et al. (2011) summarised previous model simulations and found relations which amount to $-1.65 \pm 0.36$ and -1.70 , respectively. However, these values refer to the global air traffic, whereas we consider here emissions in the upper troposphere and lower stratosphere of the northern Atlantic region during winter. Grewe and Stenke (2008) give a value of around -1 at those altitudes and latitudes.

To summarise, the lifetime of simulated $\mathrm{NO}_{\mathrm{x}}$ and $\mathrm{O}_{3}$, the ratio between the $\mathrm{NO}_{\mathrm{x}}$ emission and ozone contribution, the resulting specific $\mathrm{RF}$, and the ratio between the ozone and methane RF show large variabilities between the individual time-region grid points, and values published in the literature are well within this range.

The water vapour specific emission $\mathrm{RF}$ is $5.5 \times$ $10^{-11} \mathrm{~mW} \mathrm{~m}^{-2}\left(\mathrm{~kg}\left(\mathrm{H}_{2} \mathrm{O}\right) \mathrm{a}^{-1}\right)^{-1}$ ranging from 0.5 to $20 \times$ $10^{-11} \mathrm{~mW} \mathrm{~m}^{-2}\left(\mathrm{~kg}\left(\mathrm{H}_{2} \mathrm{O}\right) \mathrm{a}^{-1}\right)^{-1}$. For a fleet with $170 \mathrm{Tg}$ of fuel used per year this leads to an RF of $12 \mathrm{~mW} \mathrm{~m}^{-2}$ with a range of $1-43 \mathrm{~mW} \mathrm{~m}^{-2}$. Here the value of Lee et al. (2010) of $3 \mathrm{~mW} \mathrm{~m}^{-2}$ is also well within this range. The recent estimate by Wilcox et al. (2012) of $0.9 \mathrm{~mW} \mathrm{~m}^{-2}$ with a range of 0.3 to $1.4 \mathrm{~mW} \mathrm{~m}^{-2}$ is at the lower end or slightly below of our extrapolation. Note again that their calculations were for the entire global fleet rather than for emissions in a particular latitude-height region, as is the case here.

\subsection{Contrails}

A variety of studies have investigated the properties of contrails (Lee et al., 2010; Heymsfield et al., 2011). Observations of contrails cover an age spectrum from seconds to hours and were performed by in situ measurement techniques and remote sensing, e.g. from satellite platforms. Here we focus on some climate-relevant contrail properties, such as ice water content and optical depth in the visible spectral range, and show a model-to-model radiative forcing benchmark test.

Both modelling and observational data vary by orders of magnitude (e.g. Kärcher et al., 2009; Schumann, 2012). In addition, direct intercomparisons are often challenging for many reasons, e.g. different environmental conditions, different sampling periods and different detection limits. For example, modelling studies often simulate a wide range of optical thickness of contrails, which, for example, cannot be detected from satellite (Marquart et al., 2003; Kärcher et al., 2009). For all these reasons, the comparison of contrail properties such as ice water content and optical thickness for a limited number of simulations can just be seen as a sanity check rather than a hard benchmark test (Grewe et al., 2012b).

Figure 10a shows observed and simulated ice water content in contrails as a cumulative probability density function. In-situ measurements from Voigt et al. (2011) (blue) and Schröder et al. (2000) (green) include 14 and 12 contrails, respectively, but nevertheless show a large variability.

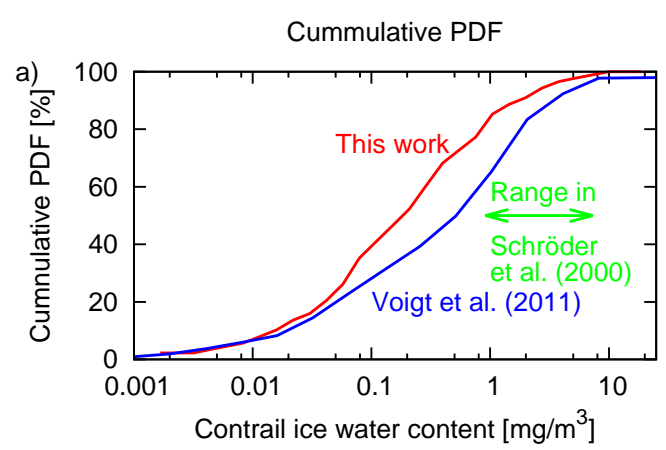

Cummulative PDF

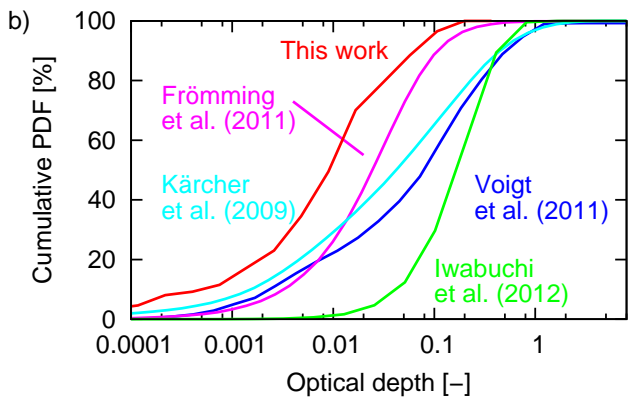

Fig. 10. Intercomparison of observed and simulated distributions of contrail properties. Estimated cumulative probability density functions of contrail ice water content $\left[\mathrm{mg} \mathrm{m}^{-3}\right]$ (a) and (b) visible optical depth.

Our simulations (88 regions of contrail formation, red) cover a similar range and show a similar distribution to Voigt et al. (2011). Kärcher et al. (2009) simulated a wide range of environmental conditions for contrail formation and found a median ice water content of $0.6 \mathrm{mg} \mathrm{m}^{-3}$ in their modelling study, which is close to our results of $0.2 \mathrm{mg} \mathrm{m}^{-3}$.

Note that the location and time of year differ in these studies. Data from Voigt et al. (2011) are obtained at $220 \mathrm{hPa}$ to $300 \mathrm{hPa}$ in central Europe in November and Schröder et al. (2000) include data in the altitude range from $300 \mathrm{hPa}$ to $200 \mathrm{hPa}$ also over central Europe, but in April/May and October, whereas here we investigate simulated contrail properties from $200 \mathrm{hPa}$ to $400 \mathrm{hPa}$ over the North Atlantic in December. We find that 88 out of 504 situations where a contrail forms, and take values of ice water content and optical properties when the contrail is fully evolved. In addition, the sampling frequency and representativity of the data with respect to the contrail area largely differs between the studies.

The cumulative probability density function of the contrail optical depth for wavelengths in the visible of these is presented in Fig. 10b. Satellite measurements (Iwabuchi et al., 2012) obligatorily deviate from in situ measurements, such as Voigt et al. (2011) and modelling studies such as Kärcher et al. (2009) and Frömming et al. (2011), because they cannot detect subvisible or thin contrails, not to mention that the sampling periods and areas are substantially different. In general, we find smaller optical depths for our specific simulated 


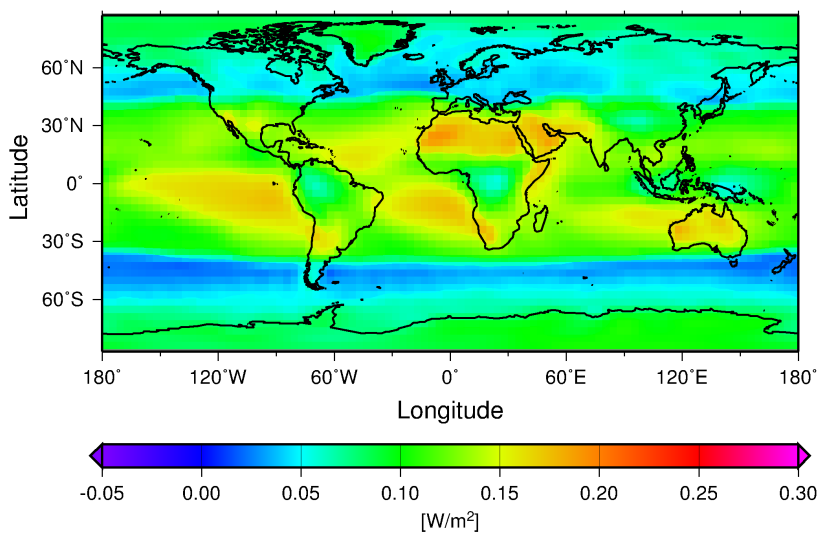

Fig. 11. Geographical distribution of the annual mean all-sky net radiative forcing at the top of the atmosphere for a homogeneous $1 \%$ contrail cover simulated with EMAC according to the benchmark test by Myhre et al. (2009).

day than the studies by Kärcher et al. (2009) and Frömming et al. (2011), which cover a much broader range of environmental parameters. Kärcher et al. (2010) compared simulated optical depths with a cloud model for the United States and found a median visible optical depth of 0.02 , which is closer to our simulated median visible optical depth.

We performed the RF-contrail benchmark test by Myhre et al. (2009), where a globally uniform $1 \%$ contrail coverage with an optical depth of $\tau=0.3$ in the visible spectrum at $11 \mathrm{~km}$ is prescribed. The results are shown in Fig. 11 and 12 . EMAC and ECHAM4 (E4) fall well within the variability of the all models (for details on this test for E4, see Frömming et al., 2011). EMAC has an increased number of spectral intervals compared to E4: 4 and 16 bands in the short- and longwave, compared to 2 and 6 , respectively. The difference in the longwave part of the RF between E4 and EMAC is small, but it differs significantly for the shortwave net forcing. However, both models are well within the overall range, which is encouraging, as four of the five radiative transfer models of Myhre et al. (2009) are much more sophisticated than the simplified schemes that have to be used in 3-D models.

\subsection{Metrics}

Here we compare the results for three common climate metrics (AGWP20, AGWP100 and AGTP50) for ozone and methane (see Sect. 3.5) with results presented in Fuglestvedt et al. (2010). They analysed the GWP and GTP of ozone and methane (i.e. the AGWP and AGTP of ozone and methane normalised with the related AGWP and AGTP of $\mathrm{CO}_{2}$ ) for different time horizons for a $1 \mathrm{yr}$ pulse emission of $\mathrm{NO}_{\mathrm{x}}$. We normalise the values with the respective metric for $\mathrm{CO}_{2}$ (Table 8) to obtain the respective GWP and GTP values. For all metrics the ozone values are well within the range of previous
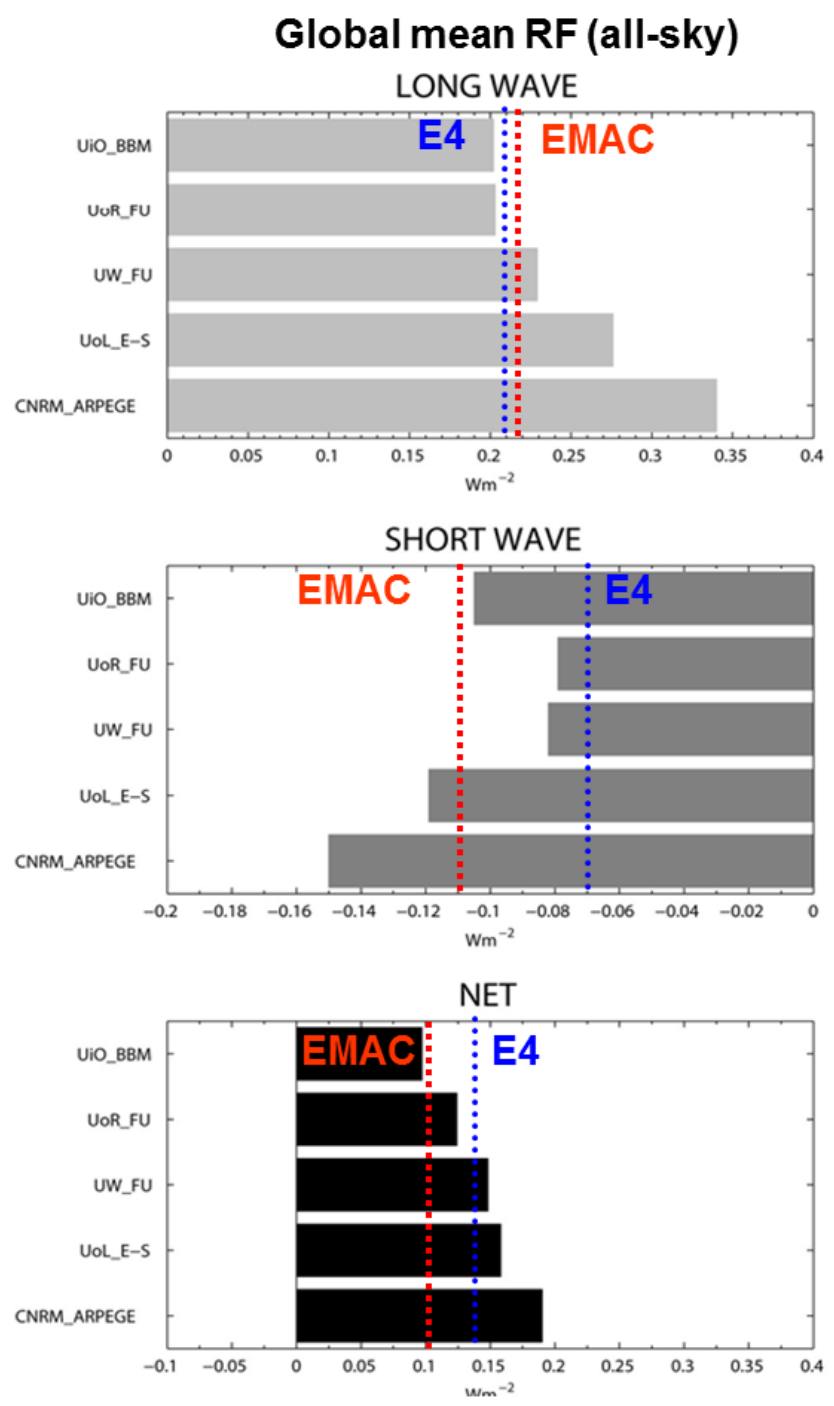

Fig. 12. Global means for the longwave (top), shortwave (mid) and net RF (bottom) for the contrail RF benchmark test (see text for details). Figure is adapted from Myhre et al. (2009).

studies. As already reported in Sect. 4.1, the regarded region (mid- to high latitudes in the tropopause region) is characterised by a stronger methane loss per ozone enhancement than for the whole air traffic (Grewe and Stenke, 2008). Hence the methane metric values are at the lower end of the values reported in Fuglestvedt et al. (2010).

To obtain an overall assessment of the metric results (here P-AGWP20), we take the transatlantic air traffic emissions, calculated with the SAAM model for the minimum economic cost, and compare these results with an AirClim simulation based on the same emission data. AirClim is a fast climatechemistry response model (Grewe and Stenke, 2008; Grewe and Dahlmann, 2012) which takes into account annual mean emissions and their regional different effects (basically latitudes and altitudes) based on a number of precalculated cases 
Table 8. Comparison of simulated GWP20, GWP100 and GTP50 values for ozone (short-lived only) and methane for emissions of $\mathrm{NO}_{\mathrm{x}}$ in the domain indicated in Table 2 with results from three different studies published in Fuglestvedt et al. (2010), abbreviated as F10.

\begin{tabular}{lcccccc}
\hline & \multicolumn{2}{c}{ GWP20 } & \multicolumn{2}{c}{ GWP100 } & \multicolumn{2}{c}{ GTP50 } \\
& Ozone & Methane & Ozone & Methane & Ozone & Methane \\
\hline $\mathrm{F} 10$ & $670 / 1100 / 1800$ & $-460 /-490 /-850$ & $190 / 300 / 510$ & $-160 /-170 /-320$ & $33 / 52 / 88$ & $-75 /-85 /-190$ \\
$200 \mathrm{hPa}$ & 1050 & -880 & 300 & -310 & 51 & -150 \\
$250 \mathrm{hPa}$ & 760 & -1060 & 220 & -370 & 37 & -180 \\
$300 \mathrm{hPa}$ & 890 & -1110 & 250 & -390 & 43 & -190 \\
$400 \mathrm{hPa}$ & 860 & -1060 & 240 & -370 & 42 & -180 \\
\hline
\end{tabular}

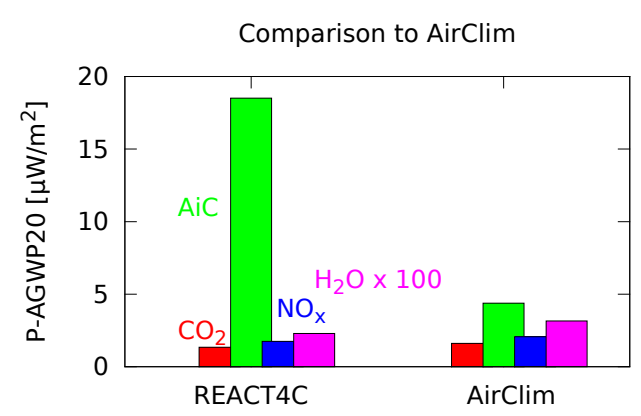

Fig. 13. Comparison of the pulse absolute global warming potential (P-AGWP20) in $\left[\mu \mathrm{W} / \mathrm{m}^{2}\right]$ for emissions of $\mathrm{CO}_{2}$ (red), contrail cirrus (green), $\mathrm{NO}_{\mathrm{x}}$ (blue) and $\mathrm{H}_{2} \mathrm{O}$ (magenta). Note that the $\mathrm{H}_{2} \mathrm{O}$ values are multiplied by 100 for presentational purposes. The emissions from the minimum economic cost one-day transatlantic air traffic, which are calculated with SAAM, are multiplied with the climate cost functions (REACT4C, left) and taken as annual mean emissions for the climate-chemistry response model AirClim (right).

with complex chemistry-climate modelling. Note that in REACT4C the climate response takes the specific weather situation into account, whereas in the case of the AirClim simulation, the emissions are assumed to occur everyday at the same place, i.e. identical for all weather situations throughout a year. The results (Fig. 13) show almost identical values for all emission components, except for contrail cirrus, which is reasonable, since the day-to-day variability of the contrail effects are highly variable and a one-day simulation cannot be expected to be representative of the whole year. However, the comparison shows that the overall results are comparable in magnitude.

\subsection{Aircraft trajectory}

As an illustration, Fig. 14 shows various flight options for one city pair connection (Washington to Vienna). The flight on that day (light brown) clearly follows the jet stream (arrows). We have performed an optimisation of the whole transatlantic air traffic with respect to short-term climate impacts (question Q2 in Table 7, with option 3 GWP20) and costs, and we obtain a different aircraft trajectory for the above-mentioned city pair (blue), which more closely follows the jet stream. However, when the traffic is cost-optimised and includes conflict avoidance, as in reality, then the real route (light brown) and the cost-optimal (cheapest) route within conflictfree traffic (dark brown) are much closer. The difference in distance and time is around $1 \%$ and in fuel about $3 \%$.

For this city pair, the climate optimal routes (with and without conflict avoidance) with respect to short-term climate impact (see above) are located further north and at lower flight altitudes (FL330 and FL310). The conflict-free, climate-optimised route (green) avoids more contrails and leads to a decrease in contrail AGWP20 by $16 \%$ and a decrease in $\mathrm{NO}_{\mathrm{x}}$ AGWP20 by $4 \%$ with an increase in fuel consumption by $14 \%$, which is related to an increase in GWP20 from $\mathrm{CO}_{2}$ by $1 \%$.

This is one essentially random example for a particular weather pattern, a particular city pair and a particular choice of climate metrics. Beyond the fact that "climate-friendly" routes can indeed differ from the least-cost routes, no general conclusions can be drawn from this one example. It is the aim of REACT4C to produce a more systematic analysis across weather conditions and metrics.

\section{Conclusions}

We have developed a simulation framework for investigating climate change mitigation options for air traffic routing by avoiding climate-sensitive regions. It includes three major steps: the calculation of climate cost functions, the simulation and optimisation of air traffic according to these climate cost functions, and the estimation of the total mitigation gain. The climate cost functions describe the air traffic's contribution to climate change, which is caused by an emission at a certain time and location in the atmosphere. The processes we are regarding are ozone formation, methane loss, methane-induced ozone change, contrails (including the spread into cirrus), water vapour and carbon dioxide.

The simulation of physical and chemical processes is described using the chemistry-climate model EMAC, which we extended via two submodels AIRTRAC and CONTRAIL. They are described in detail in the Supplement (Frömming et al., 2013). By using the Lagrangian transport scheme 


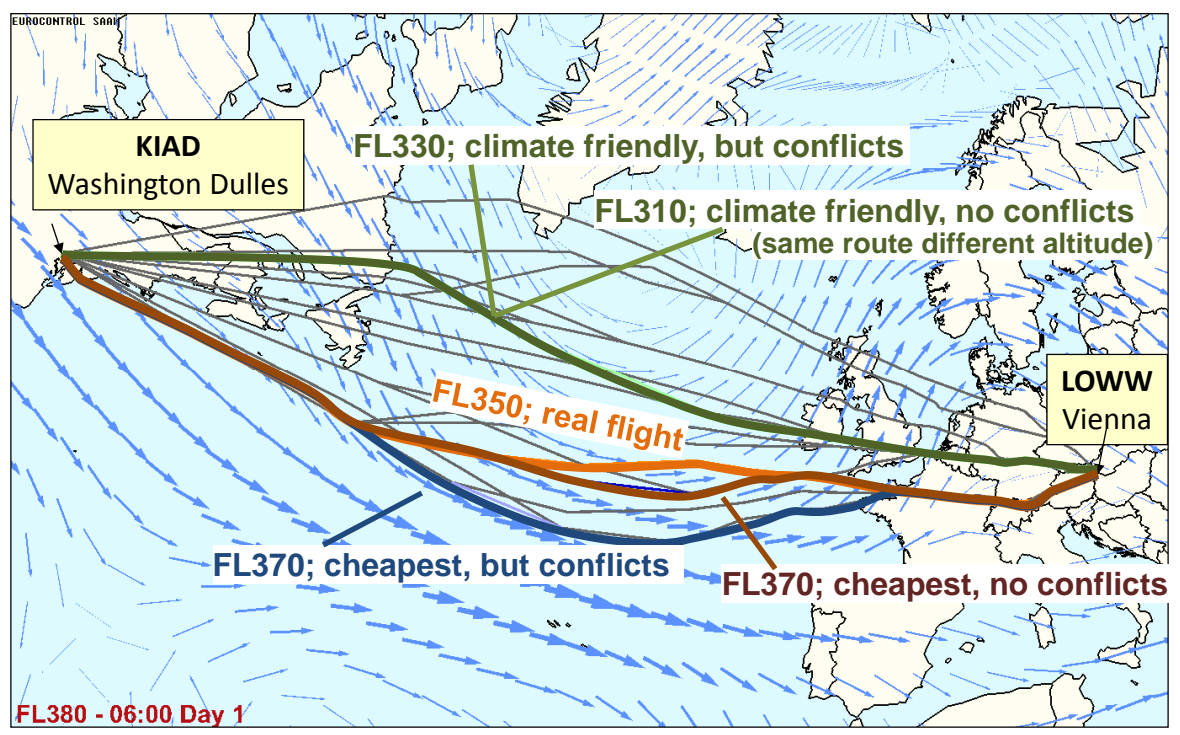

Fig. 14. Examples of climate-optimised flights. The optimisation was performed with respect to question Q1 (short-term climate impacts, AGWP20, see Table 7) for one particular winter weather pattern (zonally strong jet). The selected city pair connection is Washington to Vienna. The real flight at that day is shown in light brown. The economic optimal flights without conflict avoidance is given in blue and the conflict avoidance is given in dark brown. The climate optimal flights are shown in green. In this case the aircraft trajectories with and without conflict avoidance differ only in cruise altitude. Arrows indicate the wind field at flight level 380 , i.e. $38000 \mathrm{ft}$.

ATTILA, we were able to simulate a climate cost function at a multitude of grid points in one simulation. We used state-of-the-art chemistry and microphysics for the simulation. New is the way in which the model is used and how the climate cost functions are calculated, which required a few new considerations, e.g. regarding the calculation of the radiative forcing. We developed a parameterisation, which relates the radiation changes caused by a 15 min pulse emission to an adjusted radiative forcing for ozone.

We demonstrated the methodology for one specific simulated day in December which was characterised by a strong zonal jet stream over the Atlantic. We calculated the 4-D climate cost function data set and optimised the transatlantic air traffic with respect to economic costs and climate impact. Unfortunately a validation is hardly possible, since observational data for relations between emissions at flight altitude and climate impact is not available. Instead, we performed a sanity check of our calculated data and compared our results to previous studies, knowing that the comparison is very crude. In detail, we compared our calculated contribution of an emission at a very specific location and time to published results based on global and mostly annual air traffic emissions. Nevertheless, the ranges of, for example, contribution of $\mathrm{NO}_{\mathrm{x}}$ emissions to ozone and RF, contrail properties, etc., compare well with values from the literature.

It is important to note that uncertainties are associated with the calculation of the climate cost functions. For the optimisation, the absolute values of the climate costs are less important. More important is the relation of the climate impact of individual components and the spatial and temporal variability. In general, the uncertainty of a mean value and of any sensitivity is not necessarily correlated. Stevenson et al. (2006) showed in a multi-model intercomparison that the simulated ozone burden and methane lifetime have quite some variability but that the models very consistently simulate sensitivities. Grewe and Dahlmann (2012) intercompared results of the effect of flight altitude changes on ozone, water vapour and contrails based on Grewe and Stenke (2008), Köhler et al. (2008) and Rädel and Shine (2008) and found similar sensitivities for ozone and contrails, but larger ones for water vapour and methane.

The calculated climate cost functions will form the basis for a detailed analysis of the climate change mitigation potential of the air traffic system. First results indicate that a large potential already exists at present to significantly reduce the contribution of air traffic to anthropogenic climate change. In future publications we will investigate this potential in more detail. The optimisation with respect to climate might be an extreme scenario. Nonetheless, small changes to the air traffic system, i.e. the change in routing of a few very climate-sensitive flights, might already yield a large reduction of the air traffic's climate impact through reduction of contrail and $\mathrm{NO}_{\mathrm{x}}$ effects and with only small increases in fuel consumption. However, such conclusions are influenced greatly by the overall objective or, in other words, the aim of any climate change policy, which in turn controls the choice of the climate emission metric and the choice of time horizon for those metrics. Some choices would put a greater value on 
reducing the forcing due to short-lived components such as contrails and $\mathrm{NO}_{\mathrm{x}}$, whilst others would put a greater value on reducing the forcing due to the longer-lived emissions, notably $\mathrm{CO}_{2}$. A necessity for the operational implementation of the methodology would be a reliable forecast of weather conditions in advance of the route-planning procedures and confidence that specific conditions, such as the occurrence of regions of ice supersaturation, could be forecast at the necessary level of detail.

\section{Appendix A}

\section{Calculation of the adjusted radiative forcing for ozone}

In this section we provide a methodology to calculate radiative forcings which will serve as an input to the climate metric calculations (Sect. 3.5). Since we are considering relatively short pulse emissions, previous approaches have to be adapted. For all species, except for contrails, we consider the adjusted radiative forcing (e.g. Hansen et al., 1997). For ozone this requires new considerations, which are presented in the following sections. For contrails the difference between instantaneous and adjusted radiative forcing is small (Marquart, 2003) and neglected here.

\section{A1 General approach for adjusted radiative forcing for ozone}

Radiative forcing is the common metric to intercompare the global mean impacts of various components contributing to total climate change. As emphasised in previous works (Hansen et al., 1997; Stuber et al., 2001), the so-called stratosphere-adjusted radiative forcing (also known as the fixed dynamical heating approximation; Forster et al., 1997) is generally a better quantification than the instantaneous forcing for the climate impact that is to be expected from an ozone perturbation near or above the tropopause. Other definitions of radiative forcing are available (see e.g. Gregory et al., 2002), but these require lengthy climate model calculations and are not easily applicable to the relatively small radiative forcings due to aviation. The basic equation is

$\Delta T_{\text {surf }}^{\mathrm{eq}}=\lambda \mathrm{RF}_{\mathrm{adj}}$,

which relates the global mean stratosphere-adjusted radiative forcing $\mathrm{RF}_{\text {adj }}$ in $\left[\mathrm{W} \mathrm{m}^{-2}\right.$ ] linearly to the global mean equilibrium surface temperature response $\Delta T_{\text {surf }}^{\mathrm{eq}}$ in $[\mathrm{K}] . \mathrm{RF}_{\text {adj }}$ is the radiative imbalance (at the tropopause or at the top of the atmosphere) induced by the forcing perturbation, determined after the stratosphere has re-adjusted to thermal equilibrium. $\lambda$ in $\left[\mathrm{K}\left(\mathrm{W} \mathrm{m}^{-2}\right)^{-1}\right]$ is the climate sensitivity parameter which has been assumed, initially, to be a universal constant, independent of the nature or the distribution of the perturbation. If the instantaneous forcing $\mathrm{RF}_{\text {inst }}$ instead of $\mathrm{RF}_{\mathrm{adj}}$ is used in Eq. (A1), $\lambda$ becomes strongly perturbationdependent and even the sign of the radiative forcing may become inconsistent with the resulting surface temperature response in the case of an ozone perturbation at higher altitudes (e.g. around $20 \mathrm{~km}$ ) (Hansen et al., 1997). The necessity to quantify perturbations in terms of $\mathrm{RF}_{\text {adj }}$ poses a specific problem for the methodology used in the present study: $\mathrm{RF}_{\text {adj }}$ cannot be directly calculated for a pulse perturbation, as such a perturbation is not stationary, meaning that the stratospheric temperature cannot adjust to a new equilibrium. In contrast, $\mathrm{RF}_{\text {inst }}$ could easily be determined, even in such a case, at any location of the parcel in space and time, as no temperature adjustment is needed for calculating the instantaneous radiative flux change induced by a changing absorber. However, because we regard each of our short-lived perturbations as part of aviation climate impact as a whole (when stratospheric temperature adjustment are non-negligible), it has to be assessed by a metric consistent with $\mathrm{RF}_{\mathrm{adj}}$. In the following we will discuss a thought experiment that illustrates the problem. The general idea is to translate an instantaneous radiative forcing $\mathrm{RF}_{\text {inst }}$ resulting from a pulse emission into an equivalent stratosphere-adjusted radiative forcing $\mathrm{RF}_{\mathrm{adj}}$ by means of an analytical formula:

$\mathrm{RF}_{\text {adj }}=f_{1}(t) \times f_{2}(p) \times \mathrm{RF}_{\text {inst }}$.

The unitless functions $f_{1}$ and $f_{2}$ describe the relation between $\mathrm{RF}_{\text {adj }}$ and $\mathrm{RF}_{\text {inst }}$ for various times of the year $\left(f_{1}\right.$, seasonal cycle) and various perturbation altitudes $\left(f_{2}\right)$ and are derived from additional idealised simulations.

\section{A2 Thought experiment}

Let us assume we consider two alternative flight routings, implying emissions in two different time regions. We want to answer the following question: "which routing induces the lower climate impact?" Let us further assume we had the same meteorology everyday. The constraint from this thought experiment is then that the decision on the preferable routing is identical everyday.

We now investigate two different assessment approaches, which both should lead to the same choice of routing. Figure $\mathrm{A} 1$ shows $\mathrm{RF}_{\text {inst }}$ (green) of a short pulse emission, e.g. as originating from $\mathrm{NO}_{\mathrm{x}}$ emissions of one individual flight. The pulse is short compared to the temperature adjustment time of the stratosphere and a temperature adjustment is not yet achieved. One can regard this period as a spin-up for $\mathrm{RF}_{\mathrm{adj}}$, during which the adjusted and instantaneous RFs are still equal. Both $\mathrm{RF}_{\text {inst }}$ and $\mathrm{RF}_{\mathrm{adj}}$ are positive in this case. A sequence of individual pulses (flights), occurring every 0.005 time units, will also lead to a positive, though higher, $\mathrm{RF}_{\text {inst }}$ (blue). In this case, however, the continuous sequence of pulses gradually induces stratospheric temperature adjustment, reducing $R F_{\text {adj }}$ with respect to $R F_{\text {inst }}$ over time until it eventually becomes - in this example, which is geared to ozone effects - negative ( $-2 \mathrm{RF}$ units, magenta). Thus, the assessment of an individual flight as part of a sequence of the same flights, and with the same meteorology everyday, has to 
Table A1. Abbreviations.

\begin{tabular}{ll}
\hline AEM & Advanced Emission Model \\
ATTILA & Atmospheric Tracer Transport in a Lagrangian Model \\
BADA & Base of Aircraft Data \\
CCF & Climate cost function \\
GFED & Global Fire Emissions Database \\
ECHAM & ECMWF general circulation model - Hamburg version \\
ECMWF & European Centre for Medium-Range Weather Forecasts \\
EMAC & ECHAM/MESSy Atmospheric Chemistry \\
PMO & Primary-mode ozone \\
RAD & Route availability document \\
REACT4C & Reducing emissions from aviation by changing trajectories for the benefit of climate \\
RETRO & REanalysis of the TROpospheric chemical composition over the past $40 \mathrm{yr}$ \\
RF & Radiative forcing \\
SAAM & System for traffic Assignment and Analysis at a Macroscopic level \\
\hline
\end{tabular}

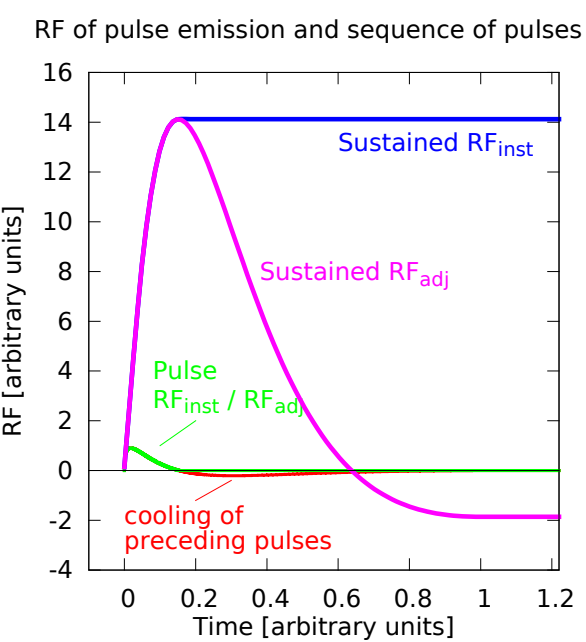

Fig. A1. Schematic view of the radiative forcing due to ozone as a result of a pulse emission of $\mathrm{NO}_{\mathrm{x}}$ compared to a sequence of pulse emissions (i.e. sustained emissions). Instantaneous and adjusted RF of a short pulse emission are identical (green). Instantaneous RF of a sequence of pulse emissions (blue) is calculated as the sum of the instantaneous RF of pulse emissions. Adjusted RF of a sequence of pulse emissions (magenta) is calculated similarly, i.e. as the sum of the RF of a sequence of pulse emissions, where the cooling effect of preceding pulses is parameterised (red).

reflect this negative RF. Its time developing radiative impact consists of contributions of varying strength and sign, and it contains an additional tail of negative values (red line). This contribution must be included for the assessment of the flight in terms of its time-averaged RF.

As mentioned, such an equivalent $\mathrm{RF}_{\text {adj }}$ cannot be gained directly from the individual pulse simulation. We overcome this dilemma by calculating a response function (Eq. A2) to obtain a parameterised $R F_{a d j}$, transferring $R F_{\text {inst }}$ to $R F_{\text {adj }}$ by means of precalculated temperature adjustment effects from various types of pulse perturbation. The terms of the response functions can be obtained from idealised simulations that calculate $\mathrm{RF}_{\mathrm{adj}}$ and the associated stratospheric temperature adjustment from a limited number of typical ozone perturbations located at various altitudes and latitudes, and under various conditions of insolation.

\section{A3 Simulation setup}

Three idealised ozone perturbation patterns (see Supplement) are considered, which were adopted from previous simulations evaluating a number of emissions, located in various latitude-height bands (Fichter, 2009). The $\mathrm{NO}_{\mathrm{x}}$ emissions basic to the ozone patterns discussed here occurred at altitudes of 200, 160 and $130 \mathrm{hPa}$, within the Northern Hemisphere extratropics (see Supplement for more details). Radiative forcing calculations were performed with EMAC for each perturbation pattern over a $1 \mathrm{yr}$ period, preceded by a 3-month spin-up for the adjustment of stratospheric temperatures. The simulations include a calculation of the adjusted as well as the instantaneous RF. Each of the 12 months is interpreted as an individual pulse, and the $\mathrm{RF}_{\text {inst }}$ and $\mathrm{RF}_{\mathrm{adj}}$ that it induces can be directly compared from the simulation, and the difference between $\mathrm{RF}_{\text {inst }}$ and $\mathrm{RF}_{\text {adj }}$ can be determined for each calender month.

Additionally, we have extended the simulation by four simulations for the second year, where we have successively switched off the ozone perturbation after January, April, July and October. These simulations are used to quantify the contribution of the adjusted stratospheric temperatures to the RF calculations after the perturbation has faded out. As soon as the perturbation pattern is removed in the respective (second simulation) month, the only contribution to the RF arises from the remaining stratospheric temperature changes, which revert to the unperturbed situation rather fast. It turned out that this contribution to $\mathrm{RF}_{\mathrm{adj}}$ is only of minor importance and thus we could omit it for the sake of simplicity. 

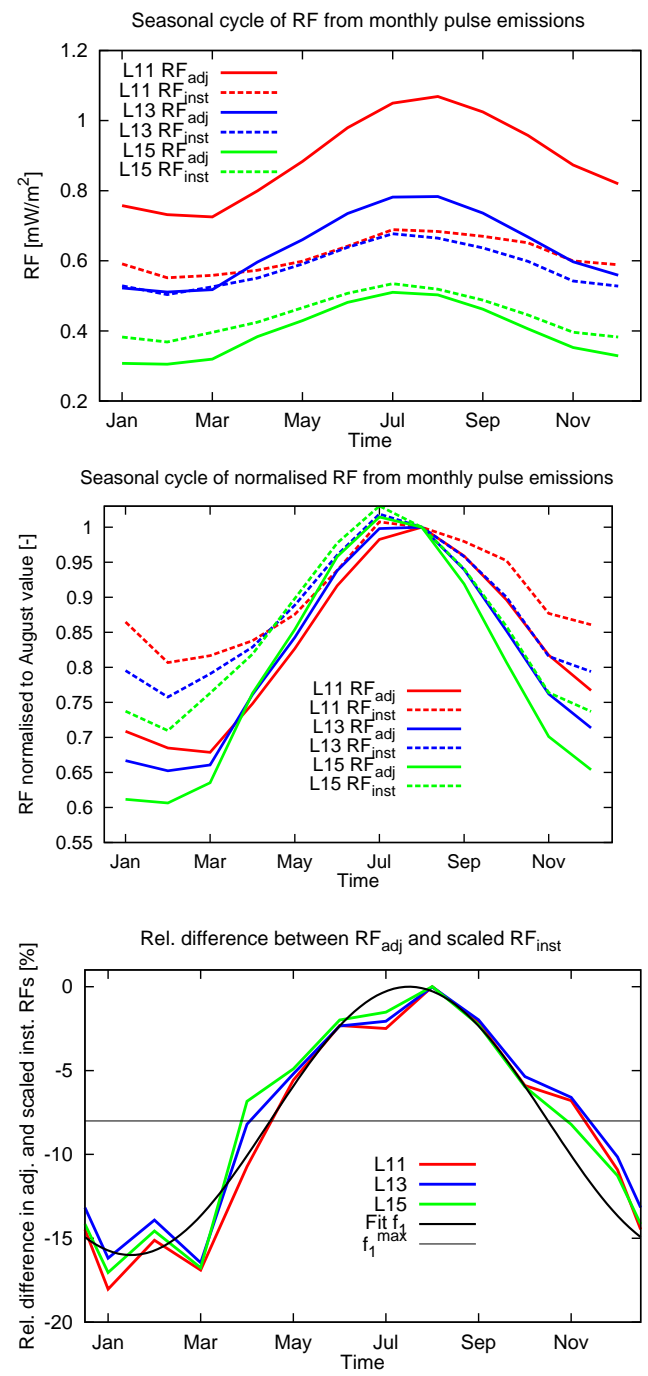

Fig. A2. Annual cycle of the radiative forcing due to ozone change of a pulse emission of $\mathrm{NO}_{\mathrm{x}}$. The $\mathrm{NO}_{\mathrm{x}}$ emission which produces the monthly change pattern, is located at $130 \mathrm{hPa}(\mathrm{L} 11$, red), $160 \mathrm{hPa}$ (L13, blue) and $200 \mathrm{hPa}$ (L15, green). Dashed lines refer to instantaneous RF and solid ones to adjusted RF. (a) Seasonal cycle of RF. (b) as (a), but normalised to the individual August value. (c) Relative difference [\%] of the adjusted RF and the scaled instantaneous RF. The scaling factor is the quotient of the respective August values. The black line shows a sine fit $f_{1}$ (see Eq. (A3)).

\section{A4 Separation of height and time dependencies}

Figure A2a shows the seasonal cycle of the radiative forcing (both $\mathrm{RF}_{\text {inst }}$ and $\mathrm{RF}_{\text {adj }}$ ) as caused by a $\mathrm{NO}_{\mathrm{x}}$ pulse emission over one month (see Supplement for the respective ozone pattern). As explained in Sect. $A 3, R_{\text {adj }}$ values imply the assumption that preceding emissions induced a stratospheric temperature adjustment before the considered pulse was initiated. A distinct annual cycle is obvious, reflecting the insolation variation that directly effects the shortwave component

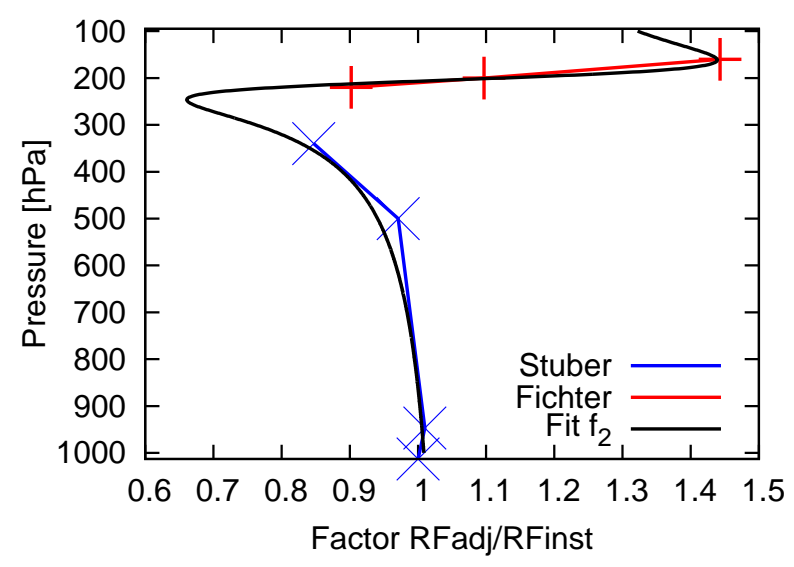

Fig. A3. Height dependence of the relation between instantaneous and adjusted RF for annual mean RF values of changes in ozone. Data are taken from Stuber (2003) and Fichter (2009). Ozone changes are mainly found in the Northern Hemisphere (see also the Supplement).

of the radiative forcing. The contribution of the stratospheric temperature adjustment to $\mathrm{RF}_{\text {adj }}$ also displays a seasonal cycle, as heating due to solar absorption by stratospheric ozone forms an important component of the adjustment. There is a general increase of RF with the altitude of the pulse emission. For pulses emitted at $130 \mathrm{hPa}$ and $160 \mathrm{hPa}, \mathrm{RF}_{\text {adj }}$ is larger than $\mathrm{RF}_{\text {inst }}$, whereas the opposite is true for an emission at $200 \mathrm{hPa}$.

Following our approach to derive a scaled instantaneous forcing serving as a proxy for $\mathrm{RF}_{\mathrm{adj}}$, we normalise all seasonal cycles to the respective August value (Fig. A2b). The ratio between these August reference values of $\mathrm{RF}_{\mathrm{adj}}$ and $\mathrm{RF}_{\text {inst }}$ is $1.56,1.18$ and 0.97 for $130 \mathrm{hPa}, 160 \mathrm{hPa}$ and $200 \mathrm{hPa}$, respectively. The relative time development becomes much more unique, and the normalised, adjusted RF is always lower than the normalised, instantaneous RF, allowing for the rescaling of $\mathrm{RF}_{\text {inst }}$ to yield the required proxy $\mathrm{RF}_{\text {adj }}$ (Eq. A2). The relative difference displays a clear seasonal cycle (Fig. A2c) with largest differences in winter (about $15 \%$ ), which can be approximated by a sine function (black line):

$f_{1}(t)=f_{1}^{\text {mean }}\left[\sin \left(2 \pi \frac{t-7.5}{12}+\frac{\pi}{2}\right)-1\right]$,

with $f_{1}^{\text {mean }}=0.08$ being the amplitude describing the deviation of peak values at summer and winter from the mean and $t$ being the month of the year. It is obvious from Fig. A2c that the approximation is largely independent of the emission altitude, justifying the approach of decomposed functions in Eq. (A2).

The altitude dependency of the relation between $\mathrm{RF}_{\text {inst }}$ and $\mathrm{RF}_{\mathrm{adj}}$ can be described from the three examples in Fig. A2a (based on simulations by Fichter, 2009, as mentioned) and five further perturbation examples of similar type previously 


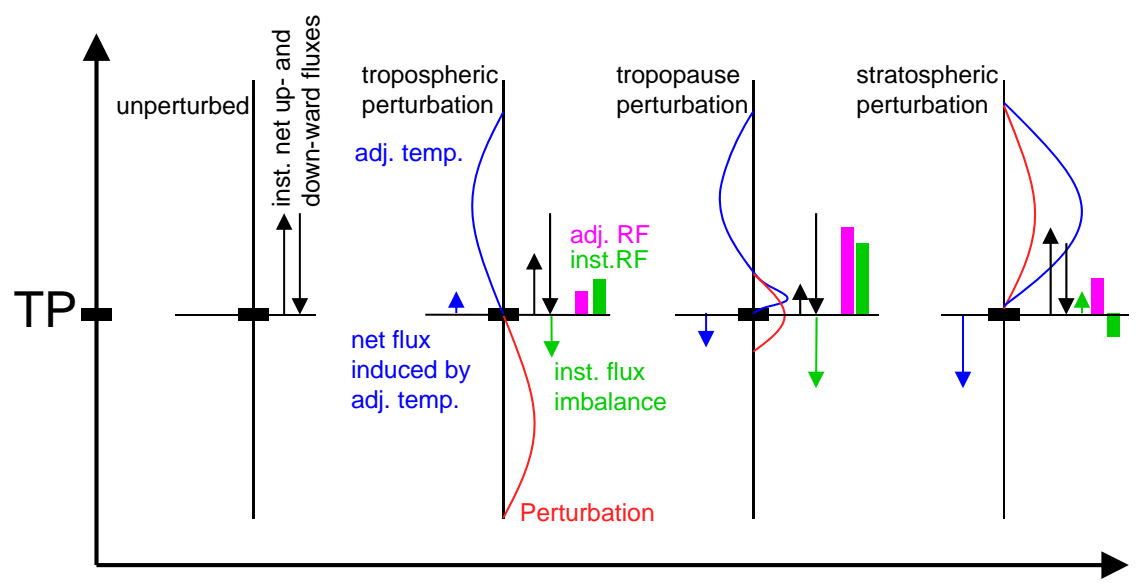

Fig. A4. Schematic of the relation between instantaneous (green bar) and adjusted RF (magenta bar) for ozone changes for four situations: unperturbed, tropospheric perturbation, tropopause perturbation and stratospheric perturbation (from left to right). The perturbation pattern is given as a red line, the instantaneous upward and downward net flux changes are given as black arrows. Net flux means the sum of longwave and shortwave fluxes. The adjusted stratospheric temperatures are shown as a blue line, and the resulting net flux changes as blue arrows. For details characterising the different cases, see the text.

evaluated by Stuber (2003). The fifth data point is at $50 \mathrm{hPa}$, and hence out of the region of interest, but used for the fit forming the parameterisation. Note that the experimental designs of Fichter (2009) and Stuber (2003) are both Northern Hemisphere ozone changes at different altitudes, though they differ in detail, especially for the prescribed ozone pattern. The results are displayed in Fig. A3. In cases where the ozone increase is exclusively located in the troposphere (i.e. below approximately $200 \mathrm{hPa}$ ), $\mathrm{RF}_{\mathrm{adj}}$ is smaller than $\mathrm{RF}_{\text {inst }}$, since the stratospheric temperature adjustment implies a cooling caused by the blanketing effect of the perturbation. In the tropopause region and in the lowermost stratosphere, an ozone increase induces a dipole-like stratospheric temperature adjustment, with warming by solar absorption where the stratospheric part of the perturbation peaks and cooling above that. The cases are also characterised by a positive instantaneous forcing at the tropopause, with longwave and shortwave contributions adding constructively (for tropospheric ozone changes), or with the positive longwave contribution dominating over a negative shortwave contribution (lowermost stratosphere). In cases where the ozone increase takes place at even higher altitudes (between $150 \mathrm{hPa}$ and $50 \mathrm{hPa}$ ), $\mathrm{RF}_{\text {inst }}$ at the tropopause becomes negative, because the effect of shortwave absorption dominates the instantaneous longwave cooling (Hansen et al., 1997; Stuber et al., 2001). $\mathrm{RF}_{\text {adj }}$ continues to be positive, however, as the warming of the stratosphere by the absorption of the upwelling longwave radiation and downwelling shortwave radiation provides an additional downward longwave flux, which for lower tropospheric ozone perturbations is strong enough to overcompensate for the instantaneous net effect. In those cases the ratio between $\mathrm{RF}_{\text {adj }}$ and $\mathrm{RF}_{\text {inst }}$ is negative (Stuber,
2003). The fit resembles the overall structure well:

$$
f_{2}(p)=C-A \frac{E p-D}{B(E p-D)^{2}+1},
$$

with $A=1.1, B=2.0, C=1.05, D=3.4, E=1 / 60$.

A summarising sketch is provided in Fig. A4: the instantaneous upward and downward net flux (net means sum of shortwave and longwave) are balanced (black arrows) in the unperturbed case (left). When introducing a tropospheric perturbation (second left, red line) the downward fluxes remain basically unchanged, but the upward longwave flux (and hence the upward net flux) is reduced. This instantaneous flux imbalance (green arrow) equals a positive instantaneous radiative forcing (green bar). This leads to a stratospheric cooling (blue line) and hence to a reduced downward longwave flux, shown as an upward net flux (blue arrow). The combination of the instantaneous radiative forcing and this flux change yields the adjusted radiative forcing, which is hence smaller than the instantaneous RF.

A perturbation near tropopause altitudes (second right, red line) is much more effective than a pure tropospheric perturbation, leading to a stronger flux imbalance (green arrow) and instantaneous RF (green bar). The adjusted stratospheric temperature, however, has a cooling and warming component (blue line) and may result in an additional longwave downward flux (blue arrow) and hence a larger adjusted RF than instantaneous RF. A pure stratospheric perturbation (right) leads to a reduced shortwave downward flux and hence a reduced net flux (black arrow). The instantaneous RF is therefore negative, while the resulting adjusted stratospheric temperatures are positive (blue line). This leads to a strong longwave downward flux (blue arrow), which overcompensates 
for the flux imbalance (green arrow) and yields a positive adjusted RF.

\section{Supplementary material related to this article is available online at http://www.geosci-model-dev.net/7/ 175/2014/gmd-7-175-2014-supplement.zip.}

Acknowledgements. This work was supported by the European Union FP7 Project REACT4C (React for climate: http://www.react4c.eu/). We gratefully acknowledge the DKRZ, where the simulations were performed under project bd0718. We thank Robert Sausen for the initiation and support of this project, Ulrike Burkhardt for discussions concerning the simulation of contrail cirrus and Christiane Voigt for providing CONCERT data. We thank Klaus Gierens (DLR-internal review) and two anonymous reviewers for many helpful comments.

The service charges for this open access publication

have been covered by a Research Centre of the

Helmholtz Association.

Edited by: O. Morgenstern

\section{References}

Berntsen, T. and Fuglestvedt, J.: Global temperature responses to current emissions from the transport sector, P. Natl. Acad. Sci. USA, 105, 19154-19159, 2008.

Burkhardt, U. and Kärcher, B.: Process-based simulation of contrail cirrus in a global climate model, J. Geophys. Res., 114, D16201, doi:10.1029/2008JD011491, 2009.

Burkhardt, U. and Kärcher, B.: Global radiative forcing from contrail cirrus, Nat. Climate Change, 1, 54-58, doi:10.1038/nclimate1068, 2011.

Burkhardt, U., Kärcher, B., Ponater, M., Gierens, K., and Gettleman, A.: Contrail cirrus supporting areas in model and observations, Geophys. Res. Lett., 35, L16808, doi:10.1029/2008GL034056, 2008.

Champougny, T., Duchene, A., Joubert, A., Lambert, J., and Minoux, M.: SOP: a decision-aid tool for Global Air Traffic Management System Optimisation, 4th ATM Seminar - Santa Fe, NM, USA, December, 2001, available at: http://atmseminar.eurocontrol.fr/past-seminars/ 4th-seminar-santa-fe-nm-usa-december-2001/papers/paper 132/view (last access: August 2013), 2001.

Dahlmann, K.: Eine Methode zur effizienten Bewertung von Maßnahmen zur Klimaoptimierung des Luftverkehrs, Dissertation, DLR-Forschungsbericht, DLR-FB-2012-05, 134 pp., 2012.

Dahlmann, K., Grewe, V., Ponater, M., and Matthes, S.: Quantifying the contributions of individual $\mathrm{NO}_{\mathrm{x}}$ sources to the trend in ozone radiative forcing, Atmos. Environ., 45, 2860-2868, doi:10.1016/j.atmosenv.2011.02.071, 2011.

Deckert, R., Jöckel, P., Grewe, V., Gottschaldt, K.-D., and Hoor, P.: A quasi chemistry-transport model mode for EMAC, Geosci. Model Dev., 4, 195-206, doi:10.5194/gmd-4-195-2011, 2011.
Eurocontrol: SAAM Reference Manual 4.2.0 Beta, Version 21-122012, edited by: Eurocontrol, p. 434, 2012.

Eurocontrol: User guide AEM-kernel, Internal Document V2.26, T07/22317TC/C1107/05, Eurocontrol, 2013.

Fichter, C.: Climate impact of air traffic emissions in dependency of the emission location and altitude, Dissertation, DLRForschungsbericht, DLR-FB-2009-22, 2009.

Forster, P. M. de F. and Shine, K. P.: Radiative forcing and temperature trends from stratospheric ozone changes, J. Geophys. Res., 102, 10841-10857, 1997.

Forster, P., Ramaswamy, V., Artaxo, P., Berntsen, T., Betts, R., Fahey, D. W., Haywood, J, Lean, J., Lowe, D. C., Myhre, G., Nganga, J., Prinn, R., Raga, G., Schulz, M., and Van Dorland, R.: Changes in atmospheric constituents and in radiative forcing, edited by: Solomon, S., Qin, D., Manning, M., Marquis, M., Averyt, K., Tignor, M. M. B., LeRoy Miller Jr., H., and Chen, Z., Climate Change 2007: the Physical Science Basis. Contribution of Working Group I to the Fourth Assessment Report of the Intergovernmental Panel on Climate Change, Cambridge University Press, Cambridge, 2007.

Frömming, C., Ponater, M., Burkhardt, U., Stenke, A., Pechtl, S., and Sausen, R.: Sensitivity of contrail coverage and contrail radiative forcing to selected key parameters, Atmos. Environ., 45, 1483-1490, 2011.

Frömming, C., Ponater, M., Dahlmann, K., Grewe, V., Lee, D. S., and Sausen, R.: Aviation-induced radiative forcing and surface temperature change in dependency of the emission altitude, J. Geophys. Res., 117, D19104, doi:10.1029/2012JD018204, 2012.

Fuglestvedt, J., Berntsen, T., Myhre, G., Rypdal, K., and Skeie, R.: Climate forcing from the transport sectors, P. Natl. Acad. Sci. USA, 105, 454-458, 2008.

Fuglestvedt, J. S., Shine, K. P., Berntsen, T., Cook, J., Lee, D. S., Stenke, A., Skeie, R. B., Velders, G. J. M., and Waitz, I. A.: Transport impacts on atmosphere and climate: metrics, Atmos. Environ., 44, 4648-4677, doi:10.1016/j.atmosenv.2009.04.044, 2010.

Gierens, K. and Spichtinger, P.: On the size distribution of icesupersaturated regions in the upper troposphere and lowermost stratosphere, Ann. Geophys., 18, 499-504, doi:10.1007/s00585000-0499-7, 2000.

Gregory, J. M., R. J. Stouffer, S. C. B. Raper, P. A. Stott, N. A. Rayner: An Observationally Based Estimate of the Climate Sensitivity. J. Climate, 15, 3117-3121, doi:10.1175/15200442(2002)015<3117:AOBEOT>2.0.CO;2, 2002.

Grewe, V.: A generalized tagging method, Geosci. Model Dev., 6, 247-253, doi:10.5194/gmd-6-247-2013, 2013.

Grewe, V. and Dahlmann, K.: Evaluating Climate-Chemistry Response and Mitigation Options with AirClim, 591-608, edited by: Schumann, U., ISBN 978-3-642-30182-7, ISBN 978-3-64230183-4 (eBook), doi:10.1007/978-3-642-30183-4, Springer, Heidelberg, New York, Dordrecht, London, 2012.

Grewe, V. and Stenke, A.: AirClim: an efficient tool for climate evaluation of aircraft technology, Atmos. Chem. Phys., 8, 46214639, doi:10.5194/acp-8-4621-2008, 2008.

Grewe, V., Dameris, M., Fichter, C., and Sausen, R.: Impact of aircraft $\mathrm{NO}_{\mathrm{x}}$ emissions. Part 1: interactively coupled climatechemistry simulations and sensitivities to climate-chemistry 
feedback, lightning and model resolution, Meteorol. Z. 3, 177186, 2002.

Grewe, V., Stenke, A., Ponater, M., Sausen, R., Pitari, G., Iachetti, D., Rogers, H., Dessens, O., Pyle, J., Isaksen, I. S. A., Gulstad, L., Søvde, O. A., Marizy, C., and Pascuillo, E.: Climate impact of supersonic air traffic: an approach to optimize a potential future supersonic fleet - results from the EU-project SCENIC, Atmos. Chem. Phys., 7, 5129-5145, doi:10.5194/acp-7-5129-2007, 2007.

Grewe, V., Tsati, E., and Hoor, P.: On the attribution of contributions of atmospheric trace gases to emissions in atmospheric model applications, Geosci. Model Dev., 3, 487-499, doi:10.5194/gmd3-487-2010, 2010.

Grewe, V., Dahlmann, K., Matthes, S., and Steinbrecht, W.: Attributing ozone to $\mathrm{NO}_{\mathrm{x}}$ emissions: implications for climate mitigation measures, Atmos. Environ., 59, 102-107, 2012a.

Grewe, V., Moussiopoulos, N., Builtjes, P., Borrego, C., Isaksen, I. S. A., and Volz-Thomas, A.: The ACCENT-protocol: a framework for benchmarking and model evaluation, Geosci. Model Dev., 5, 611-618, 2012b.

Hansen, J., Sato, M., and Ruedy, R.: Radiative forcing and climate response, J. Geophys. Res., 102, 6831-6864, 1997.

Heymsfield, A. J. and Donner, L. J.: A scheme for parameterizing ice cloud water content in general circulation models, J. Atmos. Sci., 47, 1865-1877, 1990.

Heymsfield, A., Baumgardner, D., DeMott, P., Forster, P., Gierens, K., and Kärcher, B.: Contrail microphysics, B. Am. Meteorol. Soc., 91, 465-472, doi:10.1175/2009BAMS2839.1, 2010.

Holmes, C. D., Tang, Q., and Prather, M. J.: Uncertainties in climate assessment for the case of aviation NO, P. Natl. Acad. Sci. USA, 108, 10997-11002, doi:10.1073/pnas.1101458108, 2011.

Intergovernmental Panel on Climate Change: Special report on aviation and the global atmosphere, edited by: Penner, J. E., Lister, D. H., Griggs, D. J., Dokken, D. J., and McFarland, M., Cambridge University Press, New York, NY, USA, 1999.

IPCC, Climate Change 2007 - The physical science basis. Contribution of Working Group I to the Fourth Assessment Report of the Intergovernmental Panel on Climate Change Contributions of working group I, edited by: Solomon, S., Qin, D., Manning, M., Chen, Z., Marquis, M., Averyt, K. B., Tignor, M., and Miller, H. L., Cambridge University Press, Cambridge, UK, New York, NY, USA, 2007.

Irvine, E. A., Hoskins, B. J., and Shine, K. P.: The dependence of contrail formation on the weather pattern and altitude in the North Atlantic, Geophys. Res. Lett., 39, L12802, doi:10.1029/2012GL051909, 2012.

Irvine, E. A., Hoskins, B. J., Shine, K. P., Lunnon, R. W., and Frömming C.: Characterizing north Atlantic weather patterns for climate-optimal routing, Meteorol. Appl., 20, 80-93, doi:10.1002/met.1291, 2013.

Iwabuchi, H., Yang, P., Liou, K. N., and Minnis, P.: Physical and optical properties of persistent contrails: climatology and interpretation, J. Geophys. Res., 117, D06215, doi:10.1029/2011JD017020, 2012.

Jöckel, P., Tost, H., Pozzer, A., Brühl, C., Buchholz, J., Ganzeveld, L., Hoor, P., Kerkweg, A., Lawrence, M. G., Sander, R., Steil, B., Stiller, G., Tanarhte, M., Taraborrelli, D., van Aardenne, J., and Lelieveld, J.: The atmospheric chemistry general circulation model ECHAM5/MESSy1: consistent simulation of ozone from the surface to the mesosphere, Atmos. Chem. Phys., 6, 5067-5104, doi:10.5194/acp-6-5067-2006, 2006.

Jöckel, P., Kerkweg, A., Pozzer, A., Sander, R., Tost, H., Riede, H., Baumgaertner, A., Gromov, S., and Kern, B.: Development cycle 2 of the Modular Earth Submodel System (MESSy2), Geosci. Model Dev., 3, 717-752, doi:10.5194/gmd-3-717-2010, 2010.

Kärcher, B., Burkhardt, U., Unterstrasser, S., and Minnis, P.: Factors controlling contrail cirrus optical depth, Atmos. Chem. Phys., 9, 6229-6254, doi:10.5194/acp-9-6229-2009, 2009.

Kärcher, B., Burkhardt, U., Ponater, M., and Frömming, C.: Importance of representing optical depth variability for estimates of global line-shaped contrail radiative forcing, P. Natl. Acad. Sci. USA, 107, 19181-19184, doi:10.1073/pnas.1005555107, 2010.

Köhler, M. O., Rädel, G., Dessens, O., Shine, K. P., Rogers, H. L., Wild, O., and Pyle, J. A.: Impact of perturbations to nitrogen oxide emissions from global aviation, J. Geophys. Res., 113, D11305, doi:10.1029/2007JD009140, 2008.

Lee, D. S., Pitari, G., Grewe, V., Gierens, K., Penner, J. E., Petzold, A., Prather, M. J., Schumann, U., Bais, A., Berntsen, T., Iachetti, D., Lim, L. L., and Sausen, R.: Transport impacts on atmosphere and climate: aviation, Atmos. Environ., 44, 46784734, 2010.

Mannstein, H., Spichtinger, P., and Gierens, K.: A note on how to avoid contrail cirrus, Transport. Res., 10, 421-426, 2005.

Marquart, S.: Klimawirkung von Kondensstreifen: Untersuchungen mit einem globalen atmosphärischen Zirkulationsmodell, Dissertation, DLR-Forschungsbericht 2003-16, p. 161, ISSN 14348454, Cologne, Germany, 2003.

Marquart, S., Ponater, M., Mager, F., and Sausen, R.: Future development of contrail cover, optical depth and radiative forcing: impacts of increasing air traffic and climate change, J. Climate, 16, 2890-2904, 2003.

Matthes, S.: Climate-optimised flight planning - REACT4C in Innovation for a Sustainable Avation in a Global Environment, Proceedings of the Sixth European Aeronautics Days 2011, IOS Press \& European Union, ISBN 978-92-79-22968-8, 2012.

Matthes, S., Schumann, U., Grewe, V., Frömming, C., Dahlmann, K., Koch, A., and Mannstein, H.: Climate Optimized Air Transport, edited by: Schumann, U., ISBN 978-3-642-30182-7, ISBN 978-3-642-30183-4 (eBook), doi:10.1007/978-3-642-30183-4, Springer, Heidelberg, New York, Dordrecht, London, 727-746, 2012.

Minnis, P., Young, D. F., Nguyen, L., Garber, D. P., Smith Jr., W. L., and Palikonda, R.: Transformation of contrails into cirrus durring SUCCESS, Geophys. Res. Lett., 25, 1157-1160, 1998.

Myhre, G., Kvalevåg, M. M., Rädel, G., Cook, J., Shine, K. P., Karcher, F., Markowicz, K., Kardas, A., Wolkenberg, P., Balkanski, Y., Ponater, M., Forster, P. M., Rap, A., and Rodriguez de Leon, R.: Intercomparison of radiative forcing of stratospheric water vapour and contrails, Met. Z., 18, 585-596, 2009.

Ponater, M., Marquart, S., and Sausen, R.: Contrails in a comprehensive global climate model: parameterization and radiative forcing results, J. Geophys. Res., 107, 941-960, 2002.

Rädel, G. and Shine, K. P.: Radiative forcing by persistent contrails and its dependence on cruise altitudes, J. Geophys. Res., 113, D07105, doi:10.1029/2007JD009117, 2008.

Reithmeier, C. and Sausen, R.: ATTILA - atmospheric tracer transport in a Lagrangian model, Tellus B, 54, 278-299, 2002. 
Roeckner, E., Brokopf, R., Esch, M., Giorgetta, M., Hagemann, S., Kornblueh, L., Manzini, E., Schlese, U., and Schulzweida, U.: Sensitivity of simulated climate to horizontal and vertical resolution in the ECHAM5 atmosphere model, J. Climate, 19, 37713791, 2006.

Sander, R., Baumgaertner, A., Gromov, S., Harder, H., Jöckel, P., Kerkweg, A., Kubistin, D., Regelin, E., Riede, H., Sandu, A., Taraborrelli, D., Tost, H., and Xie, Z.-Q.: The atmospheric chemistry box model CAABA/MECCA-3.0, Geosci. Model Dev., 4, 373-380, doi:10.5194/gmd-4-373-2011, 2011.

Sausen, R., Nodorp, D., and Land, C.: Towards an optimal flight routing with respect to minimal environmental impact, in: Impact of Emissions from Aircraft and Spacecraft upon the Atmosphere, edited by: Schumann, U. and Wurzel, D., Procedings of an International Science Colloquium, Köln (Cologne), Germany, 18-20 April, ISSN 0939-298X, 473-478, 1994.

Schröder, F., Kärcher, B., Duroure, C., Ström, J., Petzold, A., Gayet, J.-F., Strauss, B., Wendling, P., and Borrmann, S.: On the transition of contrails into cirrus clouds, J. Atmos. Sci., 57, 464-480, doi:10.1175/15200469(2000)057<0464:OTTOCI>2.0.CO;2, 2000.

Schumann, U.: On conditions for contrail formation from aircraft exhausts, Meteorol. Z., 5, 4-23, 1996.

Schumann, U.: Influence of propulsion efficiency on contrail formation, Aerosp. Sci. Technol., 4, 391-401, 2000.

Schumann, U.: A contrail cirrus prediction model, Geosci. Model Dev., 5, 543-580, doi:10.5194/gmd-5-543-2012, 2012.

Schumann, U., Graf, K., and Mannstein, H.: Potential to reduce the climate impact of aviation by flight level changes, 3rd AIAA Atmospheric and Space Environments Conference AIAA paper 2011-3376, 1-22, 2011.

Shine, K. P. Derwent, R. G., Wuebbles, D. J., and Morcrette, J.J.: Radiative forcing of climate, in: Climate Change: The IPCC Scientific Assessment (1990), Report prepared for Intergovernmental Panel on Climate Change by Working Group I, edited by: Houghton, J. T., Jenkins, G. J., and Ephraums, J. J., Cambridge University Press, Cambridge, Great Britain, New York, NY, USA and Melbourne, Australia, 410 pp., 41-68, 1990.
Shine, K. P., Berntsen, T. K., Fuglestvedt, J. S., and Sausen, R., Scientific issues in the design of metrics for inclusion of oxides of nitrogen in global climate agreements, Proc. Natl. Acad. Sci., 102, 15768-15773, doi:10.1073/pnas.0506865102, 2005.

Spichtinger, P., Gierens, K., Leiterer, U., and Dier, H.: Ice supersaturation in the tropopause region over Lindenberg, Germany, Meteorol. Z., 12, 143-156, 2003.

Sridhar, B., Chen, N., and Ng, H.: Energy Efficient Strategies for Reducing the Environmental Impact of Aviation, paper 212, 10th ATM-seminar, Chicago, USA, 10 pp., available at: www. atmseminar.org (last access: August 2013), 2012.

Stevenson, D. S., Doherty, R. M., Sanderson, M. G., Collins, W. J., Johnson, C. E., and Derwent, R. G.: Radiative forcing from aircraft $\mathrm{NO}_{\mathrm{x}}$ emissions: mechanisms and seasonal dependence, J. Geophys. Res., 109, D17307, doi:10.1029/2004JD004759, 2004.

Stevenson, D. S., Dentener, F. J., Schultz, M. G., Ellingsen, K., van Noije, T. P. C., Wild, O., Zeng, G., Amann, M., Atherton, C. S., Bell, N., Bergmann, D. J., Bey, I., Butler, T., Cofala, J., Collins, W. J., Derwent, R. G., Doherty, R. M., Drevet, J., Eskes, H. J., Fiore, A. M., Gauss, M., Hauglustaine, D. A., Horowitz, L. W., Isaksen, I. S. A., Krol, M. C., Lamarque, J.-F., Lawrence, M. G., Montanaro, V., Müller, J.-F., Pitari, G., Prather, M. J., Pyle, J. A., Rast, S., Rodriguez, J. M., Sanderson, M. G., Savage, N. H., Shindell, D. T., Strahan, S. E., Sudo, K., and Szopa, S.: Multimodel ensemble simulations of present-day and near-future tropospheric ozone, J. Geophys. Res., 111, D08301, doi:10.1029/2005JD006338, 2006.

Stuber, N.: Ursachen der Variabilität des Klimasensitivitätsparameters für räumlich inhomogene Ozonstörungen, Dissertation, DLR-Forschungsbericht 2003-03, 2003.

Stuber, N., Sausen, R., and Ponater, M.: Stratosphere adjusted radiative forcing calculations in a comprehensive climate model, Theor. Appl. Climatol., 68, 125-135, 2001.

Voigt, C., Schumann, U., Jessberger, P., Jurkat, T., Petzold, A., Gayet, J.-F., Krämer, M., Thornberry, T., and Fahey, D. W.: Extinction and optical depth of contrails, Geophys. Res. Lett., 38, L11806, doi:10.1029/2011GL047189, 2011.

Wilcox, L. J., Shine, K. P., and Hoskins, B. J.: Radiative forcing due to aviation water vapour emissions, Atmos. Environ., 63, 1-13, doi:10.1016/j.atmosenv.2012.08.072, 2012. 